$$
\text { CONF-960848--7 }
$$

\title{
Recent Advances in Phosphate Laser Glasses for High Power Applications
}

J. H. Campbell

$$
\begin{gathered}
\text { FeOPNDD } \\
\text { Allg } 221996 \\
\text { OSTI }
\end{gathered}
$$

This paper was prepared for submittal to the SPIE 1996 International Symposium on Optical Science,

Engineering and Instrumentation

Denver, Colorado

August 4-9, 1996

May 14, 1996

This is a preprint of a paper intended for publication in a journal or proceedings. Since changes may be made before publication, this preprint is made available with the understanding that it will not be cited or reproduced without the permission of the author.

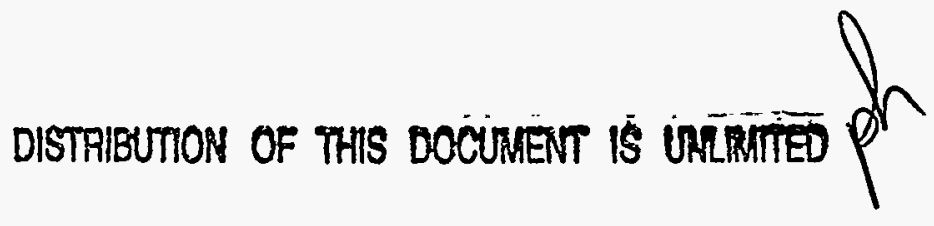




\section{DISCLAIMER}

This document was prepared as an account of work sponsored by an agency of the United States Government. Neither the United States Government nor the University of California nor any of their employees, makes any warranty, express or implied, or assumes any legal liability or responsibility for the accuracy, completeness, or usefulness of any information, apparatus, product, or process disclosed, or represents that its use would not infringe privately owned rights. Reference herein to any specific commercial products, process, or service by trade name, trademark, manufacturer, or otherwise, does not necessarily constitute or imply its endorsement, recommendation, or favoring by the United States Government or the University of California. The views and opinions of authors expressed herein do not necessarily state or reflect those of the United States Government or the University of California, and shall notbe used for advertising or productendorsement purposes. 


\section{DISCLAIMER}

Portions of this document may be illegible in electronic image products. Images are produced from the best available original document. 

Recent advances in phosphate laser glasses for high power applications

John H. Campbell

Lawrence Livermore National Laboratory, P. O. Box 808 Livermore, CA 94550, USA

\begin{abstract}
Recent advances in Nd-doped phosphate laser glasses for high-peak-power and highaverage-power applications are reviewed. Compositional studies have progressed to the point that glasses can be tailored to have specific properties for specific applications. Non-radiative relaxation effects can be accurately modeled and empirical expressions have been developed to evaluate both intrinsic (structural) and extrinsic (contamination induced) relaxation effects. Losses due to surface scattering and bulk glass absorption have been carefully measured and can be accurately predicted. Improvements in processing have lead to high damage threshold (e.g. Pt inclusion free) and high thermal shock resistant glasses with improved edge claddings. High optical quality pieces up to $79 \times 45 \times 4 \mathrm{~cm}^{3}$ have been made and methods for continuous melting laser glass are under development.
\end{abstract}

Key words: laser glass, phosphate glass, high power lasers, optical glass

\title{
1. INTRODUCTION
}

This review covers advances over the last 5 to 10 years in phosphate laser glasses developed for high-peak-power (HPP) and high-average power (HAP) applications. The manuscript is divided into four main parts:

1. a summary of laser glass properties important for high-power applications,

2. advances in understanding the effects of composition and processing conditions on key properties of phosphate laser glasses,

3. a compilation of the properties of HPP and HAP glasses and

4. improvements in the manufacturing technology that have lead to better performance and lower cost HPP and HAP laser glasses.

One additional purpose of this review is to provide useful empirical expressions or correlations for estimating the effects of compositional changes, impurities, doping levels, processing conditions, etc., on key laser glass properties. A number of these correlations have been published in the literature and a few can easily be developed from data from various sources; both types are presented here. Hopefully these correlations will be useful to both laser glass researchers as well as laser glass users.

The article deals mainly with neodymium-doped phosphate glasses since they represent the most common and largest volume of laser glass produced today. Unfortunately, in this brief manuscript it is not possible to review the exciting developments in the area of active glasses used for fiber optics and waveguided structures; the reader is referred to reviews by others in this field. ${ }^{1,2}$ Similarly in the past there have been many excellent reviews (particularly those by Weber) on other, non-phosphate, laser glasses (silicates, 
borates, fluorides, aluminates, germanates, chalcogenides, and sulfates) $)^{2-11}$ and as a consequence that material is not covered here.

Significant work on laser glass continues to occur in Russia and the Peoples Republic of China particularly at the S .I.Vavilov Optical Institute and the Shanghi Institute.

Although some of the recent work from these countries is covered here we also refer the reader to the reviews by Lunter et al ${ }^{12}$ and by $\mathrm{Gan}^{13}$.

Nd-doped phosphate glasses are preferred as a gain medium for high-peak-power lasers such as those used for Inertial Confinement Fusion (ICF) research because they have excellent energy storage and extraction characteristics and also because they have low nonlinear refractive indices. In addition, these glasses are currently the only glasses that can be manufactured in large sizes free of damaging inclusions and at relatively low cost. To meet the performance requirements for most HPP applications, the four most important characteristics of the laser glass are:

- high net gain,

- efficient energy storage at a high energy density,

- efficient extraction of the stored energy and

- high optical quality to allow the light to propagate with little or no wavefront aberration.

These same four characteristics apply to the laser glasses used in HAP applications. However, in addition, HAP glasses must be able to operate under the high thermal loading associated with rep-rated operation. Therefore good thermal-mechanical properties such as a high fracture toughness, high thermal conductivity and low thermal expansion are critical. ${ }^{10,14-16}$ The above characteristics of the laser glass can be affected by either the glass composition or the processing conditions or, in a several instances, both. Therefore, this review examines the progress in both compositional and processing development, particularly as it affects the laser glass properties.

\section{GLASS PROPERTIES IMPORTANT FOR HPP AND HAP APPLICATTONS.}

Before reviewing the advances in laser glass compositions and processing, it is important to briefly discuss the glass properties important to HAP and HPP applications. Laser glass properties are generally broken down into (1) spectroscopic and optical properties and (2) thermal-mechanical and physical-chemical properties. It can be argued that the most important spectroscopic and optical properties for HPP applications are the emission cross-section, fluorescence lifetime, and non-linear index of refraction. The emission cross-section and the fluorescence lifetime largely control the gain, energy storage and extraction efficiency of the laser glass. The non-linear index strongly impacts beam quality, particularly noise growth at the high operating intensities required for such applications as nuclear fusion research. HPP laser systems tend to be essentially "single shot" devices with several minutes or even hours between shots, therefore the glass physical properties tend to be of less importance for the end use application. However the glass physical properties can be very important to the successful manufacture and handling of HPP glasses. In the case of HAP glasses, the thermal-physical properties are nearly as important as the laser properties because of the thermal build up that occurs 
during rep-rated operation. Consequently, considerable effort is placed on optimizing the glass composition and processing to achieve the desired laser performance at the maximum possible thermal loading.

\subsection{Gain, stored energy and extraction efficiency.}

The amplification of a laser pulse passing through a laser gain medium (e.g. laser glass) of length, $z$, can be modeled using the well-known Frantz-Nodvik equation. ${ }^{17}$ This equation relates the output fluence $\left(F_{\text {out }}\right)$ to the input fluence $\left(F_{i n}\right)$ given the small signal gain $\left(G_{0}\right)$ and saturation fluence $\left(F_{s a t}\right)$ of the laser medium:

$$
F_{\text {out }}=F_{\text {sat }} \ln \left[1+G_{0}\left(\exp \left(F_{\text {in }} / F_{\text {sat }}\right)-1\right)\right]
$$

The small-signal gain of the laser glass is described by:

$$
\mathrm{G}_{0}=\exp \left(\mathrm{z}\left[\left(\sigma \mathrm{N}^{*}\right)-\alpha\right]\right)
$$

where $\sigma$ is the emission cross section $\left(\mathrm{cm}^{2}\right), \mathrm{N}^{*}$ the Nd-ion inversion density $\left(1 / \mathrm{cm}^{3}\right)$ and $\alpha$ is the transmission loss coefficient $\left(\mathrm{cm}^{-1}\right)$. To achieve a high net gain requires a high emission cross section coupled with a large population inversion density. In addition, transmission losses due to absorption by impurities or scattering from defects in the glass (or on the polished surfaces) must be kept low relative to the gain.

The term $\sigma \mathrm{N}^{*}$ is the gain coefficient, $\mathrm{g}_{\mathrm{L}}$, and is related to the stored energy density $\left(\mathrm{E}_{\mathrm{s}}=\mathrm{hvN^{* }}\right)$ and the saturation fluence $\left(\mathrm{F}_{\mathrm{sal}}=\mathrm{h} v_{1} / \sigma\right)$ of the material:

$$
\begin{aligned}
\mathrm{g}_{\mathrm{L}} & =\mathrm{N}^{*} \sigma \\
& =\left(\mathrm{h} v_{1} \mathrm{~N}^{*}\right)\left(\sigma / \mathrm{h} v_{1}\right) \\
& =\mathrm{E}_{\mathrm{s}} / \mathrm{F}_{\mathrm{sat}}
\end{aligned}
$$

where $h$ is Planck's constant ( $(\mathrm{s}-\mathrm{s})$, and $v_{1}$ the laser frequency $(\mathrm{Hz})$. Experimentally the gain coefficient $\left(\mathrm{g}_{\mathrm{L}}\right)$ is measured directly by monitoring the signal gain of a probe beam passing through the glass as it is being pumped in a laser amplifier. ${ }^{18.19}$ For example, the large flash-lamp pumped, glass laser amplifiers used in fusion energy applications typically operate with a gain coefficient of about $0.05 \mathrm{~cm}^{-1}$. The emission cross-section is determined independently from spectroscopic measurements. The phosphate glasses used in fusion applications nominally have an emission cross-section of about 3.5 to 4.0 $x 10^{20} \mathrm{~cm}^{2}$ corresponding to a saturation fluence of about $5 \mathrm{~J} / \mathrm{cm}^{2}$. The stored energy in the laser glass is computed from equation (3) to be about $0.25 \mathrm{~J} / \mathrm{cm}^{3}$.

Energy extraction from the glass is most efficient at high laser fluences, particularly fluences in excess of twice the saturation fluence. Having a glass with a high emission cross-section is desirable because efficient extraction can be achieved at lower fluence, thereby reducing the chance of laser-induced damage to the optics. Unfortunately, not all of the stored energy in the glass can be extracted even at very high fluences. ${ }^{20}$ This is due to the inhomogeneous broadening of the Nd emission. The cross-section calculated from measurements of gain saturation using the Frantz-Nodvik equation give higher emission 
cross-sections $\left(\sigma_{g s}\right)$ than those determined spectroscopically $\left(\sigma_{e m}\right)$. This is because the $\mathrm{Nd}$ site inhomogeneities in the glass lead to hole-burning, çausing the glass to saturate at a lower fluence corresponding to a higher effective cross-section. The extraction efficiency then can be defined by the ratio of the two cross-sections:

$$
\eta_{\mathrm{ext}}=\sigma_{\mathrm{em}} / \sigma_{\mathrm{gs}}
$$

Phosphate laser glasses tend to saturate much more homogeneously than do silicates and therefore the efficiency with which the energy is extracted is much higher. ${ }^{20,21}$ This is one of the reasons for the wide use of phosphate glasses in ICF applications. To be more specific, a large fraction of the cost of the large fusion research lasers is in the cost of the amplifiers. Therefore simultaneously achieving a high stored energy and efficient extraction is essential to keep the number (and cost) of the amplifiers at a minimum.

A high $\mathrm{Nd}^{3+}$ gain cross-section is often desirable for many HPP laser applications however it can also lead to some undesirable effects. For example, for large aperture HPP laser systems, a high gain coefficient can lead to low energy storage efficiency and large spatial variations in the gain distribution across the aperture due to amplified spontaneous emission. The general rule of thumb is that the product of the gain coefficient and longest dimension of the laser glass piece should not exceed a value of about 4 . In addition the $\mathrm{Nd}$ doping and fluorescence lifetime must be optimized to achieve maximum energy storage efficiency. This trade-off between high gain, good spatial gain uniformity and efficient energy storage is quite complex and is usually optimized with the use of sophisticated laser design computer codes. ${ }^{22}$

\subsection{Spectroscopic properties}

Methods for measuring the absorption and emission properties of laser glasses have been well documented (see for example reference 7). The emission cross section $\left(\sigma_{\mathrm{cm}}\right)$ and radiative lifetime $\left(\tau_{r}\right)$ are related through the expression:

$$
\sigma_{\mathrm{ern}}=\lambda^{4} \beta /\left(8 \pi \mathrm{cn}^{2} \tau_{\mathrm{r}} \Delta \lambda_{\mathrm{eff}}\right)
$$

where $\beta$ is the branching ratio (the fraction of the emitted photons at $1.05 \mu \mathrm{m}$ ), $\lambda$ the peak emission wavelength and $\Delta \lambda_{\text {eff }}$ the effective linewidth given by:

$$
\Delta \lambda_{\text {eff }}=\int I(\lambda) d \lambda / I\left(\lambda_{p}\right)
$$

The branching ratio and the peak emission wavelength are constant to within a few percent for Nd-doped laser glasses, therefore the cross-section is inversely proportional to $\mathrm{n}^{2} \tau \Delta \lambda_{\text {eff }}$

The radiative lifetime and the branching ratio are usually calculated from the measured $\mathrm{Nd}$ absorption cross-section using the well known Judd-Ofelt treatment. ${ }^{23,24}$ Caird et al ${ }^{25}$ have recently developed an alternative method for calculating the radiative lifetime from the measured fluorescence lifetime $\left(\tau_{\mathrm{em}}\right)$ and quantum yield $(\varepsilon)$ : 


$$
\tau_{\mathrm{r}}=\tau_{\mathrm{em}} / \varepsilon
$$

Caird ${ }^{25}$ and Payne et. al. ${ }^{26}$ report that the radiative lifetime determined by the Judd-Ofelt treatment and from the quantum yield method agree to within about $10 \%$ for the phosphate glasses they have measured.

In most practical applications the quantum yield is never $100 \%$ due to non-radiative relaxation mechanisms that significantly shorten the lifetime. These non-radiative losses are affected by the intrinsic properties of the laser glass as well as the care with which the glass is manufactured. ${ }^{4,25}$ Figure 1 presents a schematic view of the most important nonradiative mechanisms.

The two most important intrinsic processes are multi-phonon relaxation and concentration quenching. Concentration quenching refers to the radiation exchange between a pair of $\mathrm{Nd}$ ions (see Fig. 1). Nd concentration quenching results from the contributions of two relaxation mechanisms. One is cross relaxation in which the two ions share the energy and the second is migration of the excitation energy from one ion to the next (the socalled "hopping" mechanism - see Fig. 1). In theory the rate of relaxation due to concentration quenching varies as $1 / \mathrm{r}^{6}$ where $\mathrm{r}$ is the inter-ion distance; note that this is equivalent to the square of the $\mathrm{Nd}^{3+}$ concentration. In reality the effect of the $\mathrm{Nd}$ concentration on relaxation rate is highly glass dependent and varies from nearly linear to quadratic in phosphates and from quadratic to cubic in silicates. ${ }^{425-27}$ Stokowski $^{4}$ and Payne et. al. ${ }^{27}$ have proposed an empirical relationship to characterize concentration quenching in HPP metaphosphate glasses:

$$
\tau_{\mathrm{em}}=\tau_{\mathrm{o}} /\left(1+(\mathrm{N} / \mathrm{Q})^{2}\right)
$$

where $\tau_{0}$ is the $\mathrm{N}$ is the $\mathrm{Nd}^{3+}$ ion concentration $\left(\mathrm{cm}^{-3}\right)$ and $\mathrm{Q}\left(\mathrm{cm}^{-3}\right)$ is an empirically determined quantity for a given glass; $Q$ is physically equivalent to the $\mathrm{Nd}$ concentration needed to reduce the lifetime to one-half its zero concentration limit. The parameter $Q$ seems to be correlated with the emission bandwidth (Fig 2); this correlation provides a handy method for estimating concentration quenching effects in new phosphate laser glasses in the absence of Nd-doping data. To explain this correlation, Payne has argued that because the rate of concentration quenching is related to the extent of spectral overlap between the two adjacent $\mathrm{Nd}$ ions, then greater concentration quenching rates would be expected for glasses with broader emission bandwidths.

The rate of multi-phonon relaxation depends on how closely the ${ }^{4} \mathrm{~F}_{32}$ to ${ }^{4} \mathrm{I}_{15 / 2}$ energy $\left(5500 \mathrm{~cm}^{-1}\right)$ matches the maximum vibration energy of the glass matrix. ${ }^{4,25,28}$ For phosphate glasses the maximum vibration energy is about $1170-1200 \mathrm{~cm}^{-1}$ based on Raman spectra by Toratani et. al..$^{29,30}$ Work by Layne et. al. ${ }^{28}$ showed that the multiphonon relaxation rates in a $67 \mathrm{P}_{2} \mathrm{O}_{5}-15 \mathrm{Na}_{2} \mathrm{O}-18 \mathrm{BaO}$ phosphate glass is only about $150 \mathrm{~s}^{-1}$. Other data also suggest the multi-phonon rate is low; these come from the extrapolated "zero-Nd" lifetime measured on dry, high-purity glasses. These lifetimes compares well with the radiative lifetime determined by the Judd-Ofelt treatment, thus suggesting the absence of any significant multi-phonon effects. Careful measurements by Caird et. al. ${ }^{25}$ 
(a) Intrinsic processes $\mathrm{Nd} \rightarrow \mathrm{Nd}$ concentration quenching
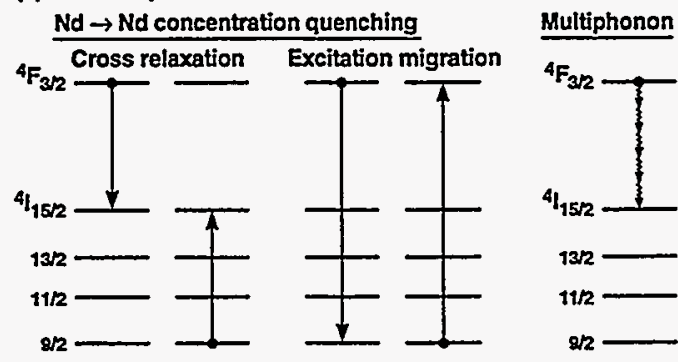

(b) Extrinsic processes Nd $\rightarrow$ transition-metal ion
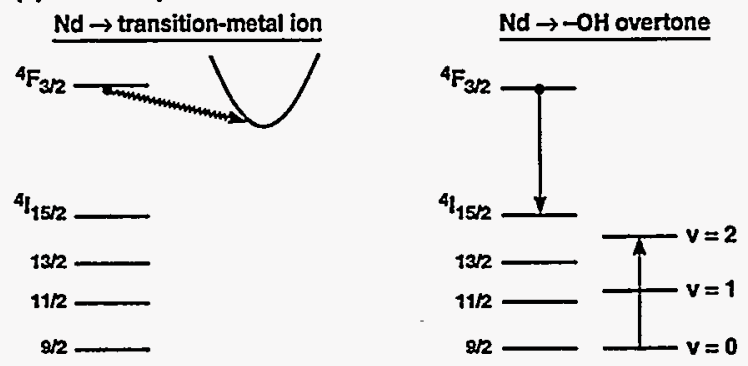

10000506-1 135ptor

15 Aticinem

Figure 1. Non-radiative $\mathrm{Nd}^{3+}$ relaxation processes in laser glasses can be divided into (a) intrinsic processes that depend on the glass structure during manufacturing and (b) extrinsic processes that depend on impurities in the laser glass (e.g. - $\mathrm{OH}$ and transition metal ions).

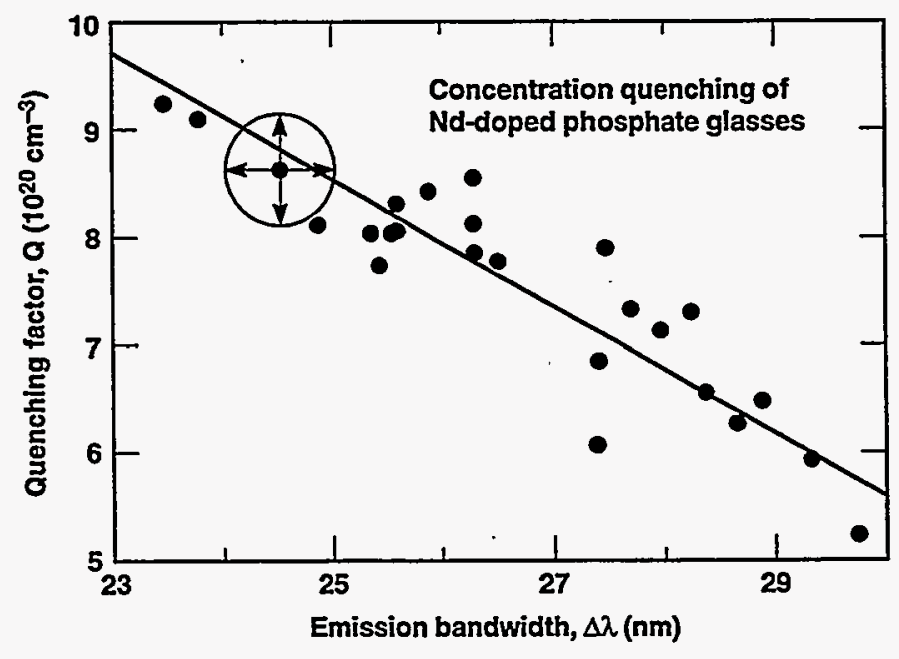

40-00-0596-11340601

$15 \mathrm{HC} / \mathrm{mam}$

Figure 2. Correlation between the Nd concentration quenching factor $(Q)$ and the measured emission bandwidth for a series of multi-component metaphosphate laser glasses. $^{27}$ 
on two commercial phosphate glasses (LG-750 and LG-760) support this observation; the measured multi-phonon relaxation rate is about $200 \mathrm{~s}^{-1}$.

It is well known that impurities that enter the glass during manufacturing (particularly $\mathrm{OH}$ and transition metal ions) can cause significant non-radiative relaxation. More is said about this later and some useful correlations are presented for estimating the impact of various impurities on the non-radiative relaxation rate in phosphate glasses (see section 3.3). We hasten to add however that the problems associated with impurities have been largely eliminated in modern laser glass manufacturing by the proper chose of raw material and melting equipment.

Many of the measured fluorescence lifetimes reported in the literature are not corrected for radiation trapping effects. Radiation trapping simply refers to the process whereby some portion of the emitted energy is reabsorbed by surrounding unpumped $\mathrm{Nd}^{3+}$ ions and then re-emitted. Thus the measured fluorescence lifetime increases with increasing sample size. Even small samples ( $<$ few $\mathrm{mm}$ ) can show a measurable increase particularly at higher doping levels. Payne et. al. ${ }^{26.27}$ suggest a simple expression for accurately correcting for radiation trapping effects:

$$
\tau_{c}=\tau_{\mathrm{T}}\left(1-\mathrm{aV}^{1 / 3}\right)
$$

where $\tau_{\mathrm{T}}$ is the measured lifetime with radiation trapping, $\tau_{\mathrm{c}}$ the corrected value, $\mathrm{V}$ the sample volume $\left(\mathrm{mm}^{3}\right)$ and, a, an empirically derived constant $\left(0.023 \mathrm{~mm}^{-1}\right)$.

\subsection{Non-linear refractive index}

The energy extraction efficiency for HPP applications is also limited by non-linear propagation effects, particularly at very short pulse lengths. The refractive index increases with the laser intensity:

$$
\mathrm{n}=\mathrm{n}_{\mathrm{o}}+\boldsymbol{\gamma} \mathrm{I}
$$

where $\gamma$ is the non-linear refractive index coefficient $\left(\mathrm{m}^{2} / \mathrm{W}\right)$ and $I$ is the laser intensity $\left(W / m^{2}\right)$. The intensity dependent index can cause amplitude ripples (noise), that occur at certain spatial frequencies, to grow exponentially:

$$
I=I_{0} \exp (B)
$$

where the "B" factor (or "break-up integral") is the cumulative non-linear phase retardation over the optical path length:

$$
B=2 \pi / \lambda \int \gamma I d z
$$

Past experience has shown that $B$ needs to be less than about 2 radians to avoid unacceptable noise ripple growth. ${ }^{31,32}$ Such growth can cause optical damage and/or degrade the beam focus. Therefore laser glasses with low non-linear indices are required for HPP applications. 
Direct measurement of $\gamma$ is difficult, so empirical correlations have been developed. The expression developed by Boling et. al. ${ }^{33}$ a number of years ago accurately predicts $\gamma$ from the refractive index $\left(n_{d}\right)$ and the Abbe number $(v)$ of the glass:

$$
\gamma=K\left(n_{d}-1\right)\left(n_{d}^{2}+2\right)^{2} /\left\{n_{d} v\left[1.52+\left(n_{d}^{2}+2\right)\left(n_{d}+1\right) v / 6 n_{d}\right]^{1 / 2}\right\}
$$

where $\mathrm{K}=2.8 \times 10^{-10} \mathrm{~m}^{2} / \mathrm{W}$ is an empirically determined constant. The non-linear refractice index, $\mathrm{n}_{2}$ (in esu) is related to $\gamma$ by $\mathrm{n}_{2}=\gamma(\mathrm{nc} / 40 \pi)$ where $\mathrm{c}$ is light speed.

\subsection{Thermal-optical properties.}

The laser glass must have high optical homogeniety to achieve the beam quality necessary to propagate and focus the laser output beam. Thermal variations in the laser glass can produce optical distortion by changing the optical path length. Therefore it is desirable in many applications (particularly rep-rated glass rod amplifiers) to have a glass in which the temperature coefficient of the optical path length is zero; these are often referred to as athermal glasses. The change in the optical path length, $\Delta \mathrm{O}_{\mathrm{L}}$, resulting from a temperature variation, $\Delta T$, is given by:

$$
\Delta \mathrm{O}_{\mathrm{L}}=\delta \mathrm{L} \Delta \mathrm{T}
$$

where $\delta$ is the temperature coefficient of the optical path length:

$$
\delta=\mathrm{dn} / \mathrm{dT}+(\mathrm{n}-1) \alpha_{\mathrm{c}}
$$

The temperature change in refractive index $(\mathrm{dn} / \mathrm{dT})$ is defined by

$$
\mathrm{dn} / \mathrm{d} T=\left[\left(\mathrm{n}^{2}-1\right)\left(\mathrm{n}^{2}+2\right) / 6 \mathrm{n}\right](\phi-\beta)
$$

where $\phi$ is the temperature dependent coefficient of electronic polarizability $\left(\mathrm{K}^{-1}\right)$ and $\beta$ is the volumetric thermal expansion coefficient $\left(\mathrm{K}^{-1}\right)$. For an isotropic material such as glass, $\beta=3 \alpha_{e}$ where $\alpha_{e}$ is the coefficient of linear thermal expansion. An ideal athermal glass has $\delta=0$ implying, from equation [15], $\mathrm{dn} / \mathrm{dT}=(\mathrm{n}-1) \alpha_{e}$. Therefore, a good athermal laser glass must have a dn/dT value about half the value of the coefficient of linear thermal expansion.

\subsection{Thermal-mechanical properties}

HAP glasses experience high thermal loading and as a consequence require a combination of good thermal-mechanical properties as well as good laser properties. ${ }^{14,29,34}$ The figureof-merit parameter used to characterize the performance of a HAP glass is the thermal shock resistance:

$$
\mathrm{R}_{\mathrm{S}}=\mathrm{k}(1-\mu) \mathrm{K}_{1 \mathrm{C}} /\left(\mathrm{E} \alpha_{\mathrm{e}}\right)
$$

where $E$ is Young's modulus, $k$ the thermal conductivity, $K_{1 c}$ the fracture toughness, $\mu$ Poisson's ratio and $\alpha_{e}$ the coefficient of linear thermál expansion. The $R_{S}$ parameter is 
obtained by combining the material properties in the well know expression for stress in a cooled plate ${ }^{35}, \sigma_{\mathrm{T}}$ :

$$
\sigma_{\mathrm{T}}=\mathrm{E} \alpha_{\mathrm{c}}(\Delta \mathrm{T}) /(1-\mu)
$$

with those in Fourier's law for heat conduction ( $q=k \Delta T)$ and Griffith's model for crack growth in brittle solids $\left(\sigma_{c}=K_{1} d\left[\pi r_{c}\right]^{1 / 2}\right)$ where $r_{C}$ is the critical flaw size. Sometimes $r_{C}$ is included in the figure-of-merit parameter to emphasize the need to keep surface flaws due to finishing, handling or laser damage at a minimum. The thermal shock resistance is directly related to the maximum thermal load that a surface cooled glass slab can tolerate before catastrophic fracture.

HPP glasses do not need to meet the high thermal loading operating requirements of HAP glasses. Nevertheless, HPP laser glasses can be subjected to thermal loads during processing and it is believed that glasses having higher thermal shock resistance will give higher process yields (and lower costs). Elder et. al. ${ }^{36}$ suggest the use of the thermal shock resistance for evaluating laser glasses for fusion laser applications. They proposed the parameter $R_{A}$, which consists of a combination of the thermal shock resistance parameter and the glass transition temperature $\left(T_{g}\right)$, as a figure-of-merit for evaluating which glasses may give the shortest fine annealing cycle:

$$
R_{A}=R_{S} / T_{g} .
$$

In general the higher the value of $R_{a}$ the easier the glass is to fine anneal.

\subsection{Chemical properties: Durability and Pt solubility}

Two chemical properties of laser glass critical for both HAP and HPP applications are the chemical durability ${ }^{36,37}$ and the Pt solubility ${ }^{38}$. The former is generally characterized by measuring the solubility of the glass in water under some well-defined condition. Maximizing the glass composition to achieve high durability eases the problems encountered with finishing, cleaning, storing and handling the laser glass. The less durable glasses are more easily stained and fogged and can lead to optical damage or higher transmission losses or both. This in turn requires costly refinishing or the installation of expensive environmental controls within the laser system.

The solubility of Pt in a specific laser glass is an important measure of the tendency of the glass to be able to be manufactured free of Pt inclusions. ${ }^{38.39} \mathrm{Pt}$ crucibles or Pt lined vessels are required for the manufacture of high optical homogeneity laser glass.

Unfortunately, small inclusions of Pt often enter the glass during the melting process and ultimately lead to catastrophic optical damage at high laser operating fluences. ${ }^{40}$ It has been found that phosphate glasses tend to dissolve these Pt inclusions when manufactured under oxidizing conditions. ${ }^{41,42}$ Therefore phosphate glass compositions with higher $\mathrm{Pt}$ solubility tend to be easier to manufacture free of $\mathrm{Pt}$ inclusions. 


\section{PROGRESS IN THE DEVELOPMENT OF HPP GLASSES.}

\subsection{Phosphate laser glass composition studies}

In general, no one laser glass composition fulfills the needs of all HPP laser applications. Laser glasses are usually tailored for specific applications and, in fact, laser glass manufacturers typically develop a suite of glasses with different laser, optical and thermal mechanical properties that covers a range of potential HPP applications. (A number of the commercially available HPP phosphate laser glasses and their properties are summarized in a section 3.8). The search for phosphate laser glasses having specific laser, optical and physical properties has become easier. This is largely because of the hundreds of glasses that have been prepared and the correlations that have been developed between specific properties and the glass composition.

The recent compositional development efforts can be divided into two main approaches. The first, more applied approach, relies on systematic variations in the composition of the glass and correlating how the composition changes affect one or more laser glass properties. The goal of much of this work is a better laser glass for a particular application. The second more basic studies are aimed at developing a quantitative understanding of glass structure and the nature of the Nd crystal field and the Nd-O metalligand bond. Advances in each of these two approaches are briefly discussed below.

Toratani, Izumitani and co-workers ${ }^{20,30,43}$ published an early systematic study of the effects of modifiers on the laser properties of ternary phosphate laser glasses. Apart from varying the composition and concentration of commonly used modifiers, they also varied the $\mathrm{P}_{2} \mathrm{O}_{5}$ content to examine the impact of changing from polyphosphate $(\mathrm{O} / \mathrm{P}>3)$ to metaphosphate $(\mathrm{O} / \mathrm{P}=3)$ to ultraphosphate $(\mathrm{O} / \mathrm{P}<3)$ compositional space. A number of useful correlations are developed for estimating the impact of alkali, alkaline-earths and alumina on the radiative and non-radiative properties of phosphate glasses as well as various optical and physical properties. The Hoya work is particularly useful because it was one of the first to correlate laser glass properties with the well known cation electric field strength (see for example Fig 3 ). The electric field strength is a parameter developed by glass chemists for correlating the effects of the modifier additions to the glass. It is derived from the coulombic attractive force, $\mathrm{F}$, between oxygen anions and the corresponding cations in the glass:

$$
F=\left(q_{c} q_{0} e^{2}\right) /\left(r_{0}+r_{c}\right)^{2}
$$

where $r_{o}$ and $r_{C}$ are the oxygen and cation radii $(\mathrm{cm}), q_{o}$ and $q_{c}$ are the valence charges of the anion $\left(\mathrm{O}^{-2}\right)$ and cation respectively and $e$ is the fundamental charge. Many researchers express the coulombic force for oxide systems simply as $q / a^{2}$ where $a=r_{0}+r_{C}$.

A number of more recent studies have also successfully correlated phosphate laser glass properties with the field strength parameter. Hayden et. al. ${ }^{37}$ have used a compositionaveraged electric field strength to correlate laser, optical and physical properties with changes in the modifier content of multi-component phosphate glasses. This work has 


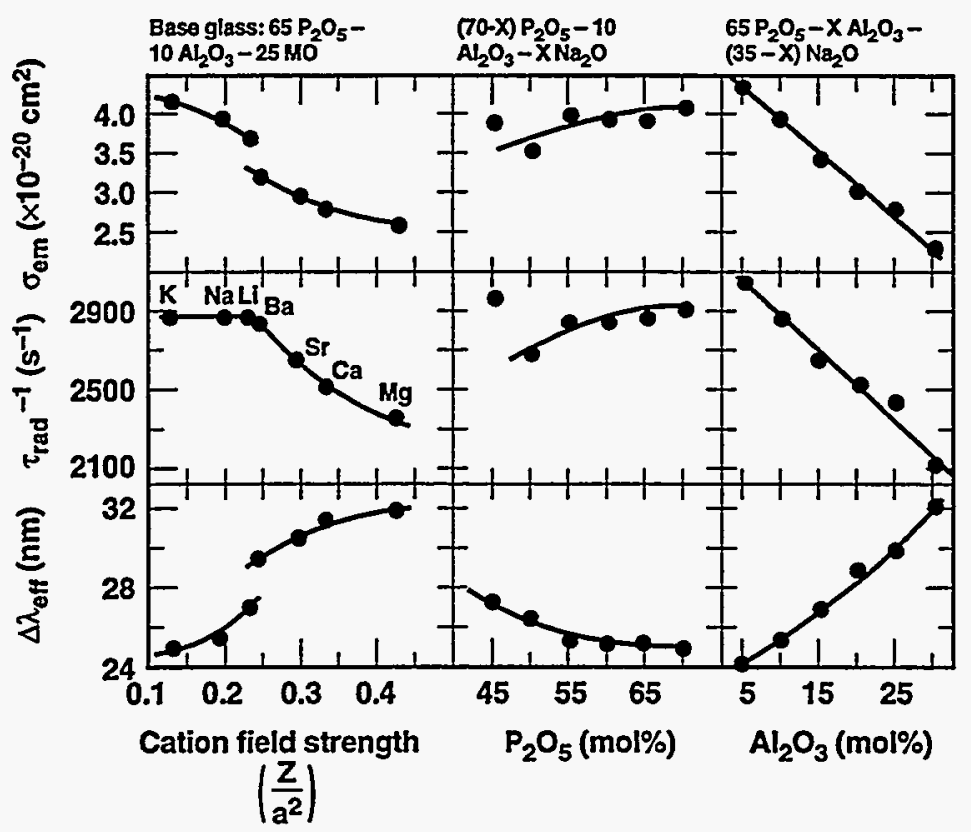

40-00-0595-1137p601

15 HC/man

Figure 3. Radiative decay rate, emission bandwidth and emission cross-section versus compositional parameters as reported by Toratani ${ }^{29,30}$ for the ternary glass systems shown.

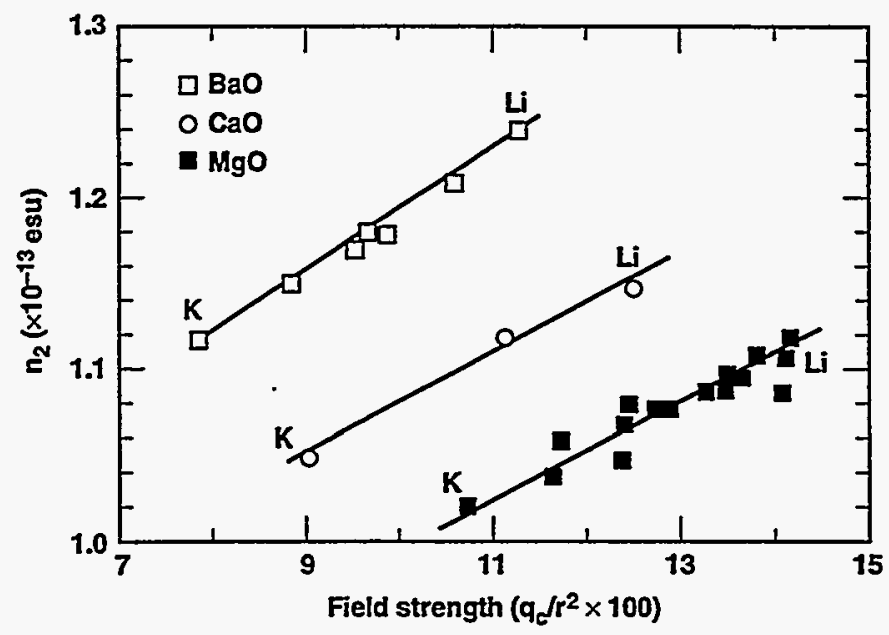

$70-000390-16500001$

$15 \mathrm{H} / \mathrm{men}$

Figure 4. Effect of systematic changes in combinations of modifiers $\mathrm{Li}, \mathrm{Na}, \mathrm{K}, \mathrm{Mg}, \mathrm{Ca}$, and $\mathrm{Ba}$ ) on $n_{2} ;$ the $n_{2}$ values computed from measured $n_{d}$ and Abbe number. ${ }^{37}$ (The glasses are derivatives of LG-750.) 


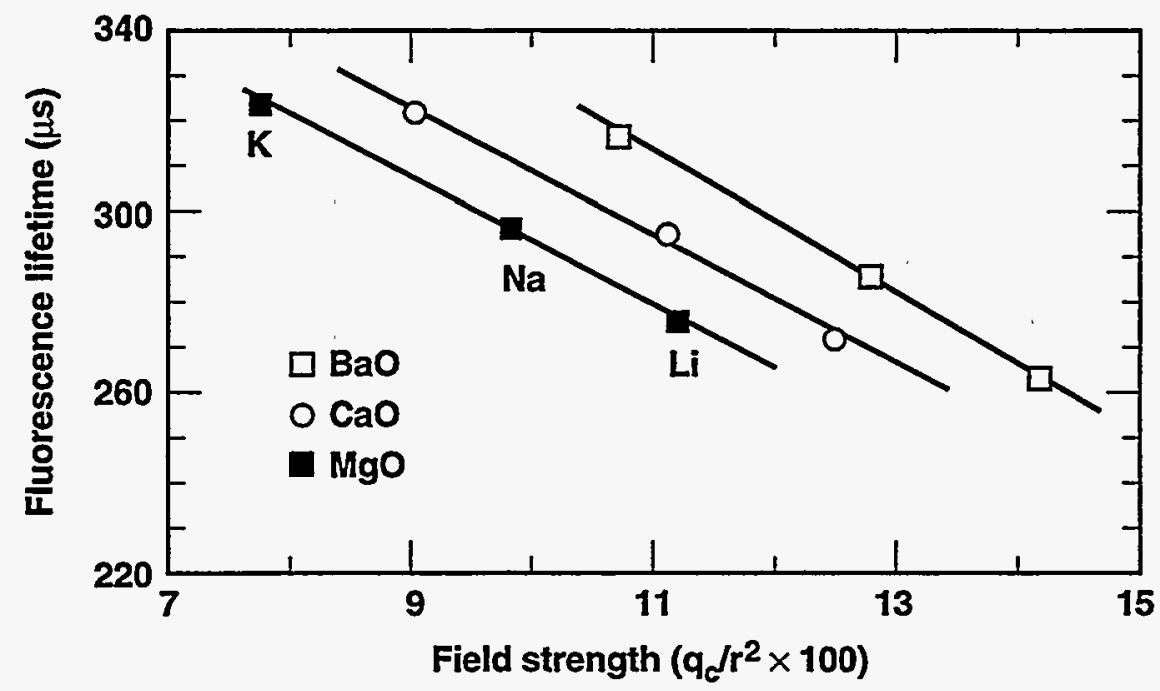

40-00-0596-1131pb01

15.JHC/mem

Figure 5. Effect of systematic changes in combinations of modifiers $(\mathrm{Li}, \mathrm{Na}, \mathrm{K}, \mathrm{Mg}, \mathrm{Ca}$, and $\mathrm{Ba}$ ) on the fluorescence lifetime. The glasses are derivatives of LG-750. ${ }^{37}$

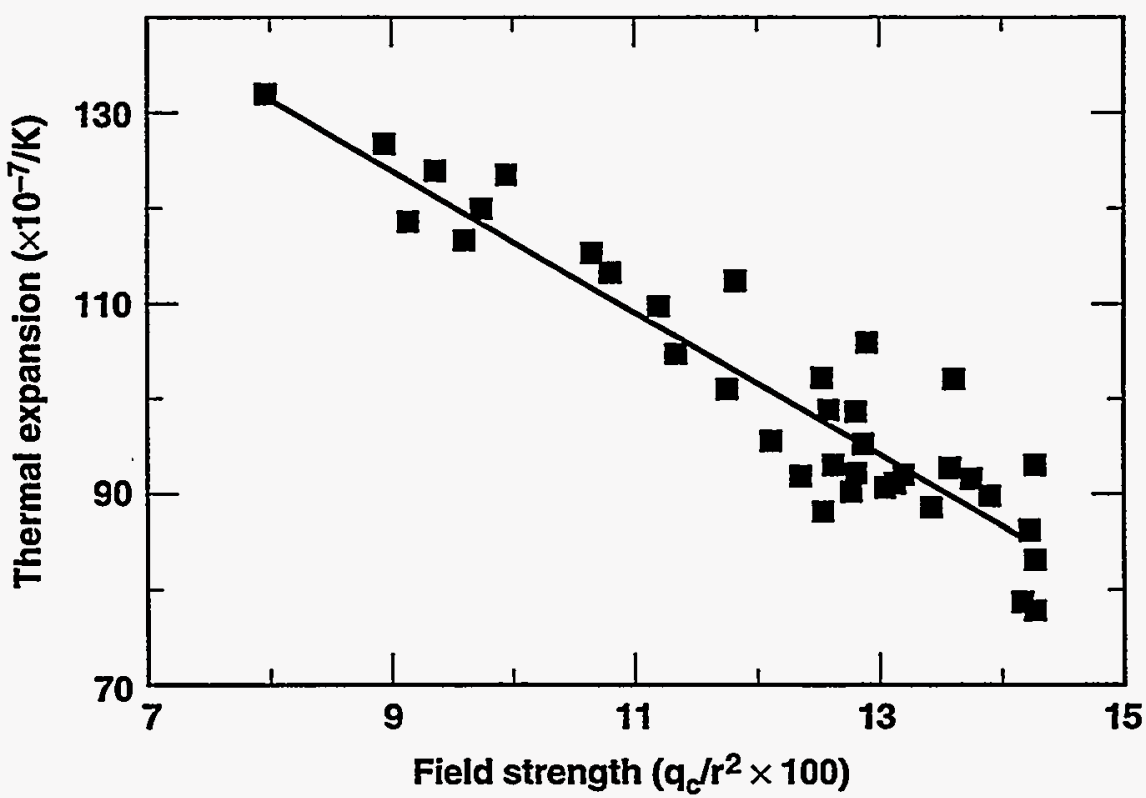

70-00-1190-3205pb01

$15 \mathrm{JHC} / \mathrm{mom}$

Figure 6. Correlation of linear thermal expansion coefficient with the compositionally averaged field strength for 41 phosphate laser glasses of varying modifier concentrations $(\mathrm{Li}, \mathrm{Na}, \mathrm{K}, \mathrm{Mg}, \mathrm{Ca}$, and $\mathrm{Ba})$. The glasses are compositional derivatives of $\mathrm{LG}-750{ }^{37}$ 
been used to identify composition changes that improve specific laser glass properties (see for example Fig. 4-6). Payne and c0-workers ${ }^{927,44}$ have also recently developed a figureof-merit approach for optimizing the properties of glasses used for fusion laser applications. By systematically varying the modifier and network former content, they have developed a laser glass composition with a low $\mathrm{n}_{2}$, good laser properties, and improved melting characteristics. This work lead to the development of a new HPP laser glass: LG-770 (see section 3.8).

Workers in China (at the Shanghai Institute of Optics and Fine Mechanics) have also studied the $\mathrm{R}_{2} \mathrm{O}-\mathrm{RO}-\mathrm{Al}_{2} \mathrm{O}_{3}-\mathrm{P}_{2} \mathrm{O}_{5}$ series of Nd-doped glasses. ${ }^{13}$ Their compositional development work has culminated in the production of large pieces $(70 \mathrm{~mm}$ rods and 300 $\mathrm{mm}$ disks) of two phosphate glasses $\left(\mathrm{N}_{21}\right.$ and $\left.\mathrm{N}_{24}\right)$. The properties of these glasses are summarized in a review by Gan. ${ }^{13}$ The Shanghi Institute researchers are the first to report the effects of $\mathrm{BeO}$ as a modifier in phosphate glasses. Although $\mathrm{BeO}$ is not a good modifier from a practical sense, this data provides a useful extension of the effects of group II metal oxides on laser glass properties. For example, Figure 7 shows the effect of a systematic change in modifiers from $\mathrm{Be}$ to $\mathrm{Ba}$ on $\mathrm{n}_{2}$ and the emission bandwidth for the metaphosphate glass series $55 \mathrm{P}_{2} \mathrm{O}_{5}-40 \mathrm{RO}-4.7 \mathrm{La}_{2} \mathrm{O}_{3}-0.3 \mathrm{Nd}_{2} \mathrm{O}_{3}$. The data are correlated with the radius of the cation modifier.

Recent studies by Takebe and co-workers ${ }^{45-47}$ correlate changes in the Judd-Ofelt (J-O) line intensity parameters $\left(\Omega_{2}, \Omega_{4}, \Omega_{6}\right)$ with systematic changes in the network former $\left(\mathrm{SiO}_{2}\right.$, $\mathrm{B}_{2} \mathrm{O}_{3}$ and $\left.\mathrm{P}_{2} \mathrm{O}_{5}\right)$ and modifiers $(\mathrm{Li}, \mathrm{Na} \mathrm{Mg}, \mathrm{Ca}$, and $\mathrm{Ba})$. The Judd-Ofelt parameters are related to the local structure around the rare-earth ion and are a function of basically two terms. One term describes the asymmetry of the crystal field and is related to structural changes in the vicinity of the Nd. The other term is a radial integral of $4 \mathrm{f}$ and $5 \mathrm{~d}$ wave functions and is affected by the changes in the covalent character of the Nd-O ligand bond. The $\Omega_{2}$ parameter is more sensitive to changes in the crystal field asymmetry, whereas $\Omega_{4}$ and $\Omega_{6}$ are sensitive to changes in the covalent nature of the bond. Takebe et. al. ${ }^{46,47}$ show a correlation of $\Omega_{6}$ with bond covalence and interpret this change in terms of a change in "ionic packing ratio" defined by:

$$
V_{P}=\Sigma_{i}\left(4 / 3 \pi r_{i}^{3} n_{i} N_{A}\right) / V_{M}
$$

where $r_{i}$ is the ionic radius, $n_{i}$ the mole fraction, $N_{A}$ Avagadro's number and $V_{M}$ the molar volume. They propose that the ionic packing ratio correlates with the J-O intensity parameters because it represents the "rigidity" of the glass structure and therefore the degree of covalent bonding at the rare-earth ion site.

In earlier work Toratani ${ }^{29}$ has reported values for the J-O parameters for $\mathrm{Nd}$-doped metaphosphate glasses having compositions similar to those prepared by Takebe et $\mathrm{al}^{46}$. The values of $\Omega_{2}$ and $\Omega_{6}$ determined by these two studies agree closely. This good agreement and close compositional connection between the two studies suggests that it may be possible to correlate the nephelauxetic (covalent) effects reported in Toratani's work with the results reported by Takebe et al. Toratani used $\mathrm{Pb}^{2+}$ as a probe ion to evaluate the effects of varying modifiers on the degree of covalent character in the rareearth- $\mathrm{O}$ bond. $\mathrm{Pb}^{+2}$ is a good probe ion because the $6 \mathrm{~s}-6 \mathrm{p}$ transition is sensitive to the 
degree of covalent character at the site. He shows a good correlation between the degree of covalent bonding at the probe ion site and both the electric field strength of the cation and variations in content of $\mathrm{P}_{2} \mathrm{O}_{5}$ (and $\mathrm{SiO}_{2}$ ) network former.

Tanabe et a $\mathrm{al}^{48}$ report a correlation between the ${ }^{151} \mathrm{Eu}$ Mossbauer isomer shift and the J-O $\Omega_{6}$ for $\mathrm{Nd}^{3+}$ in a number of phosphate and silicate glasses. (The glasses used in this study were the same ones prepared and studied by Toratani et al. ${ }^{20,30}$ ) The results agree with an earlier study ${ }^{49}$ that shows similar trends between $\Omega_{6}$ and the ${ }^{151} \mathrm{Eu}$ isomer shift for a range of glasses with different network formers (silicates, borates, germanates, aluminates, and alumina silicates).

Bowron et al ${ }^{50}$ studied the short range order in a series of rare earth metaphosphate glasses $\left(25 \mathrm{R}_{2} \mathrm{O}_{3}-75 \mathrm{P}_{2} \mathrm{O}_{5}\right)$. The most interesting result is an observed contraction in the diameter of the rare earth oxygen first coordination shell that corresponds to the well known atomic lanthanide contraction. The mean distance to the first and second $\mathrm{O}^{2-}$ coordination shells around Nd are reported to be $2.35 \pm 0.010$ and $3.85 \pm 0.005 \AA$, respectively.

\subsection{Quantifying absomption and scattering losses in laser glasses}

The net gain of an amplifier is a function not only of the gain coefficient but also the combined passive losses in the glass due to impurity absorption, stress-birefringence, and scattering. These losses are strongly process dependent. The major absorption losses in laser glass come from impurities that absorb at $1054 \mathrm{~nm}$. These impurities may originate from the glass raw materials, the melter refractory and/or impurities from an outside contamination source. High quality commercial laser glasses typically have an unpumped absorption loss of less than 0.001 to $0.002 \mathrm{~cm}^{-1}$ at $1054 \mathrm{~nm} .{ }^{51}$ For ICF laser systems the typical gain coefficient through a flashlamp pumped laser slab doped with 2-4 $x 10^{20} \mathrm{Nd}^{3+}$ is about $0.05 \mathrm{~cm}^{-1}$. Therefore, the ratio of gain-to-loss coefficients is always greater than 25:1 and generally greater than 50:1. To achieve these low loss levels requires the use of very high-purity raw materials as well as high-purity, low corrosion rate melter wall materials. ${ }^{52,53}$

A major fraction of the loss in the unpumped glass is due to absorption by the Nd that thermally populates the ${ }^{4} I_{1 / 2}$ terminal laser level. During flashlamp pumping this absorption loss becomes negligible because essentially all the $\mathrm{Nd}$ is in the excited state. To estimate the losses due to impurities one must correct the unpumped absorption measurements for the contribution of the Nd. Caird et. al. ${ }^{54}$ have accurately measured the absorption cross-section in LG-750 for the ${ }^{4} \mathrm{I}_{112}$ to ${ }^{4} \mathrm{~F}_{3 / 2}$ transition at room temperature to be $1.56 \pm 0.11 \times 10^{-24} \mathrm{~cm}^{2}$. In related work, Stokowski ${ }^{55}$ has measured the temperature dependence of this same transition to be $\exp (-2576 / T)$ where $T$ is the temperature $(K)$. By combining Caird and Stokowski's results, the absorption loss due to the Nd can be estimated from:

$$
\alpha_{N d}(T)=1.03 \times 10^{-20} \exp (-2576 / \mathrm{T})\left[\mathrm{Nd}^{3+}\right]
$$


where $\alpha_{\mathrm{Nd}}(\mathrm{T})$ is the temperature dependent absorption coefficient $\left(\mathrm{cm}^{-1}\right)$ and $\left[\mathrm{Nd}^{3+}\right]$ is the neodymium ion concentration (ions $/ \mathrm{cm}^{3}$ ).

Absorption measurements have been carried out on phosphate laser glasses doped with impurities, particularly common impurities such as $\mathrm{Fe}$ and $\mathrm{Cu}$ that are known to strongly absorb near $1054 \mathrm{~nm}^{29,52,53}$ Table 1 is a compilation of the absorption coefficients for a number of impurities. Contamination from $\mathrm{Cu}^{2+}$ is a concern, but can be controlled by proper analysis of raw materials. Iron is more of a concern because it is so prevalent in a manufacturing plant environment. Currently most phosphate laser glasses are processed under oxidizing conditions so iron contamination occurs as $\mathrm{Fe}^{3+}$ which is about 5 to 10 times less absorbing than $\mathrm{Fe}^{2+}$ (see Table 1).

Table 1: Absorption coefficients at $1054 \mathrm{~nm}$ for various contaminant ions measured in phosphate glasses* $\left(10^{-3} / \mathrm{cm}\right.$ per $\left.\mathrm{ppm}\right)$.

\begin{tabular}{|c|c|c|c|c|c|c|}
\hline Source: & Toratani $^{29}$ & Sto & owski e & al. ${ }^{53}$ & & t. al. ${ }^{52}$ \\
\hline Ion/Impurity & GPP* & UP-91 & UP-16 & LG-660 & LG-750 & LG-750 \\
\hline Melt atmosphere & - & $\mathrm{N}_{2}$ & $\mathrm{~N}_{2}$ & $\mathrm{~N}_{2}$ & $\mathrm{O}_{2}$ & $\mathrm{~N}_{2}$ \\
\hline $\mathrm{Cu}^{2+}$ & 2.4 & 2.3 & 2.1 & 0.38 & 2.7 & 2.1 \\
\hline $\mathrm{Fe}^{2+}$ & 2.4 & 0.7 & 0.6 & 1.1 & - & 0.55 \\
\hline $\mathrm{Fe}^{3+}$ & - & - & - & - & 0.13 & - \\
\hline $\mathrm{Co}^{2+}$ & - & 0.35 & - & 0.84 & 0.22 & - \\
\hline $\mathrm{N}_{i}^{2+}$ & 1.1 & 0.28 & - & 0.64 & 0.16 & - \\
\hline $\mathrm{V}^{3+}$ & - & 0.17 & - & 0.13 & 0.26 & - \\
\hline $\mathrm{Cr}^{3+}$ & 0.1 & & & & - & 一 \\
\hline$-\mathrm{OH}$ & 0.00081 & - & 一 & - & - & - \\
\hline $\mathrm{Pt}^{\mathrm{n+}}$ & 0.00086 & - & - & - & - & - \\
\hline $\mathrm{Mn}^{4+}$ & - & 一 & - & 0.09 & 一 & - \\
\hline$D y^{3+}$ & 0.011 & - & - & - & - & - \\
\hline $\mathrm{Sm}^{3+}$ & 0.011 & - & - & - & - & - \\
\hline * GPP: & $\mathrm{O}_{5}-18.5$ & -30 & & & & \\
\hline UP-91: & & & & $\mathrm{Nd})_{2} \mathrm{O}_{3}$ & & \\
\hline UP-16: $\quad 70 P_{2}$ & $5-20 \mathrm{~K}_{2} \mathrm{O}$ & $(\mathrm{La}+\mathrm{N}$ & & & & \\
\hline LG-660: alka & zinc-silicat & omme & al glass & & & \\
\hline LG-750: $\mathrm{Ba}$, & A1 nhong & (com & nin1 a & & & \\
\hline
\end{tabular}

Accurate measurements of bulk losses at $1.0 \mu \mathrm{m}$ in high purity laser glasses have been made possible by the use of a novel laser calorimeter. ${ }^{54,56}$ With this technique absorption values as low $1 \times 10^{-5} \mathrm{~cm}^{-1}$ can be measured on samples only a few centimeter thick.

Scatter losses are due to glass bulk inhomogeneities plus residual surface roughness after polishing. Scatter loss measurements on highly polished pieces of LHG-8 and LG-750 laser glass (typical of the polished surfaces of glasses installed in an amplifier) have been carried out using an integrating sphere scatterometer. ${ }^{54}$ The scatterometer is capable of measuring losses down to the $10 \mathrm{ppm}$ level. Combined surface and bulk scatter losses of less than $100 \mathrm{ppm}$ per sample are reported. Since the bulk scatter losses are expected to be small compared to the surface losses then a good rule-of-thumb for estimating surface 
scatter loss for finished (i.e. polished) glass parts is to assume a value of $50 \mathrm{ppm}$ per surface. This value should be used with some caution, however, because surface scatter losses can increase significantly due to contamination or optical damage once the laser glass is installed in the amplifier.

\subsection{Quantifying the effects of $-\mathrm{OH}$ and transition metals on fluorescence lifetime}

The fluorescence lifetime is strongly affected by the glass processing conditions and by impurities that may enter the glass during the maufacturing cycle. In particular, it is well known that transition metal ions and -OH groups can cause significant non-radiative relaxation. Quenching by transition metal ions is generally not a problem because of the use of high-purity raw materials and melting vessels required to meet the glass transmission specification (see previous section). Water (i.e.-OH) contamination on the other hand can be a large problem because of the hydroscopic nature of most phosphate laser glasses. To achieve the maximum fluorescent lifetime the hydroxyl content should be low enough that the absorption is less than $2.0 \mathrm{~cm}^{-1}$ at $3000 \mathrm{~cm}^{-1}\left(2850-3000 \mathrm{~cm}^{-1}\right.$ corresponds to a strong - $\mathrm{OH}$ stretching band).

Most laser glass manufacturers can meet this specification but it is often difficult for university or other researchers to prepare dry samples during small-scale test melts. Therefore it is advantageous to be able to correct the measured fluorescence decay rate for the non-radiative contribution due to -OH quenching. Several researchers have reported either - $\mathrm{OH}$ quenching rates or data from which it can be easily derived. ${ }^{4,29,57-59}$ In several cases the measurements are made as a function of Nd concentration in various phosphate glasses; Fig. 8 summarizes these data. The data are valid for $-\mathrm{OH}$ concentrations (as measured by the absorption at $\sim 2900 \mathrm{~cm}^{-1}$ ) of up to about $10 \mathrm{~cm}^{-1}$.

Payne et al. ${ }^{27}$ and Toratani ${ }^{29}$ have both suggested a simple expression for correcting for $\mathrm{OH}$ quenching in Nd-phosphate glasses:

$$
\tau^{-1}=\tau_{\text {meas }}^{-1}-\mathrm{QOH}_{\mathrm{OH}}\left(\alpha_{\mathrm{OH}}\right)
$$

where $\alpha_{\mathrm{OH}}$ is the $-\mathrm{OH}$ absorption coefficient for the strong $\sim 2800-3000 \mathrm{~cm}^{-1}-\mathrm{OH}$ stretching band and $\mathrm{Q}_{\mathrm{OH}}$ is the quenching rate $\left(\mathrm{sec}^{-1} / \mathrm{cm}^{-1}\right)$ and is a function of the Nd concentration. Over the Nd concentration range from about 2 to $3.5 \mathrm{wt} \%$ Caird ${ }^{126}$ reports that the quenching rate is approximately constant, varying between about 85 to $91 \mathrm{~s}^{-1}$ with an average of $89 \mathrm{~s}^{-1} / \mathrm{cm}^{-1}$. Payne et al. ${ }^{27}$ use this average quenching rate to correct for the effects of $-\mathrm{OH}$ on the measured fluorescence lifetime. Toratani ${ }^{29}$ reports quenching rates on a series of nine metaphosphate glasses of composition $65 \mathrm{P}_{2} \mathrm{O}_{5}-10 \mathrm{Al}_{2} \mathrm{O}_{3}-25 \mathrm{MO}$ with various modifier cations, $\mathrm{M}$, and for Nd-dopings of 0.5 and $3.0 \mathrm{wt} \% \mathrm{Nd}_{2} \mathrm{O}_{3}$. The measured $\mathrm{Q}_{\mathrm{OH}}$ values at $3.0 \mathrm{wt} \% \mathrm{Nd}_{2} \mathrm{O}_{3}$ range between 80 to $92 \mathrm{sec}^{-1} / \mathrm{cm}^{-1}$ depending on the modifier (the average value of $85 \mathrm{sec}^{-1} / \mathrm{cm}^{-1}$ is plotted in Fig. 8). At $0.5 \mathrm{wt} \% \mathrm{Nd}_{2} \mathrm{O}_{3}$ the measured $Q_{\mathrm{OH}}$ varies from about 45 to $55 \mathrm{sec}^{-1} / \mathrm{cm}^{-1}$ with an average of about 50 . One is tempted to fit the data in Fig 8 by a simple linear regression however, the rate of increase in quenching rate with increasing $\mathrm{Nd}^{3+}$ concentration appears to be slower at the low doping levels. (The dashed line in Fig. 8 is a smooth curve drawn through the data and is not based on any particular theory.) 


\begin{abstract}
Absolute measurements of -OH content in phosphate glasses are difficult, particularly at low concentrations. Conversion factors for relating the absorption coefficient at $\sim 2900$ $\mathrm{cm}^{-1}$ to absolute $-\mathrm{OH}$ concentrations vary from about 60 to nearly $400 \mathrm{ppm} / \mathrm{cm}^{-1}$ with most values between about 60 to $130 \mathrm{ppm} / \mathrm{cm}^{-1}$. This has prompted Ebendorff-Heidepreim and Ehrt ${ }^{60}$ to suggest that only absorption measurements should be used as a measure of the relative $-\mathrm{OH}$ content.
\end{abstract}

\title{
3.4 Recent studies of Nd concentration quenching in phosphate laser glasses
}

Caird et. al. ${ }^{25}$ have done a detailed analysis of concentration quenching in two commercial phosphate laser glasses: LG-750 and LG-760. They have measured the quantum efficiency over a concentration range from about 0.2 to $13 \times 10^{20} \mathrm{Nd}^{3+} / \mathrm{cm}^{3}$ and analyzed the nonradiative decay using the Förster ${ }^{61}$ model for cross-relaxation, but modified for energy migration using Burshtein's ${ }^{62}$ "hopping" model. The results show that both mechanisms are needed to accurately model the change in quantum efficiency with Nd concentration; however, cross-relaxation enhanced by energy migration appears to be the dominant relaxation mechanism in these glasses. The results of Caird's analysis give two interesting physical parameters: the critical distance $\left(R_{D D}\right)$ between Nd-ions for excitation energy transfer (i. e. hopping) and (2) the critical range for cross-relaxation $\left(R_{D A}\right) \cdot R_{D A}$ values of 4.07 and $3.52 \AA$ and $R_{D D}$ values of 11.14 and $11.37 \AA$ are reported for $L G-750$ and 760 , respectively. These critical ranges correspond to Nd-Nd inter-ionic distances at which the non-radiative decay rate equals the spontaneous emission rate. The energy migration mechanism is a resonant transfer process and the extent of spectral overlap is high; therefore it is not surprising that the $R_{D D}$ distance is quite large. On the other hand, the cross-relaxation between the ${ }^{4} \mathrm{~F}_{3 / 2}$ to ${ }^{4} \mathrm{I}_{15 / 2}$ and ${ }^{4} \mathrm{I}_{9 / 2}$ to ${ }^{4} \mathrm{I}_{13 / 2}$ states is not a resonant process and the spectral overlap is weaker. This requires the Nd-ions to be closer for efficient energy transfer. In addition ${ }^{4} \mathrm{~F}_{3 / 2}$ to ${ }^{4} \mathrm{I}_{152}$ is a weak transition, having a branching ratio of only about $0.02-0.03$ for these glasses.

Lunter et. al. ${ }^{12}$ report the effects of Group I modifier ions on the rate of concentration quenching in an ultraphosphate glass and show that the quenching increases going from Cs to $\mathrm{Li}$ (Fig. 9). Note also that the quenching rate increases linearly with Ndconcentration; this is in good agreement with other studies on ultraphosphates (e.g. see reference 4). The cross-relaxation rate in Fig 9 can be represented by the expression:

$$
\left(1 / \tau_{\text {meas }}-1 / \tau_{0}\right)=\mathrm{A}[\mathrm{Nd}]
$$

where $1 / \tau_{\text {meas }}$ is the measured transition rate, $1 / \tau_{0}$ is the rate in the absence of concentration quenching and $\mathrm{A}$ is a constant for any given cation. Fig. 10 plots the quantity A (determined from the data in Fig 9) versus the cation field strength $\left(\mathrm{Z} / \mathrm{a}^{2}\right)$; the quantities are well correlated, suggesting that the cation field strength may be a good tool for assessing which modifiers impact the rate of cross-relaxation. Jiang et al. ${ }^{58}$ report measurements of $\mathrm{Nd}^{3+}$ concentration quenching in the two glasses $18 \mathrm{~K}_{2} \mathrm{O}-10 \mathrm{Al}_{2} \mathrm{O}_{3}$ $6 \mathrm{Ln}_{2} \mathrm{O}_{3}-66 \mathrm{P}_{2} \mathrm{O}_{5}$ and $26 \mathrm{Li}_{2} \mathrm{O}-10 \mathrm{Ln}_{2} \mathrm{O}_{3}-64 \mathrm{P}_{2} \mathrm{O}_{5}$. The glass containing the $\mathrm{Li}$ modifier had a much greater quenching rate. This trend agrees qualitatively with the results in Fig. 9 and 10 , although the role of the small amount of $\mathrm{Al}_{2} \mathrm{O}_{3}$ in one of the Jiang et al. glasses raises some uncertainties. 


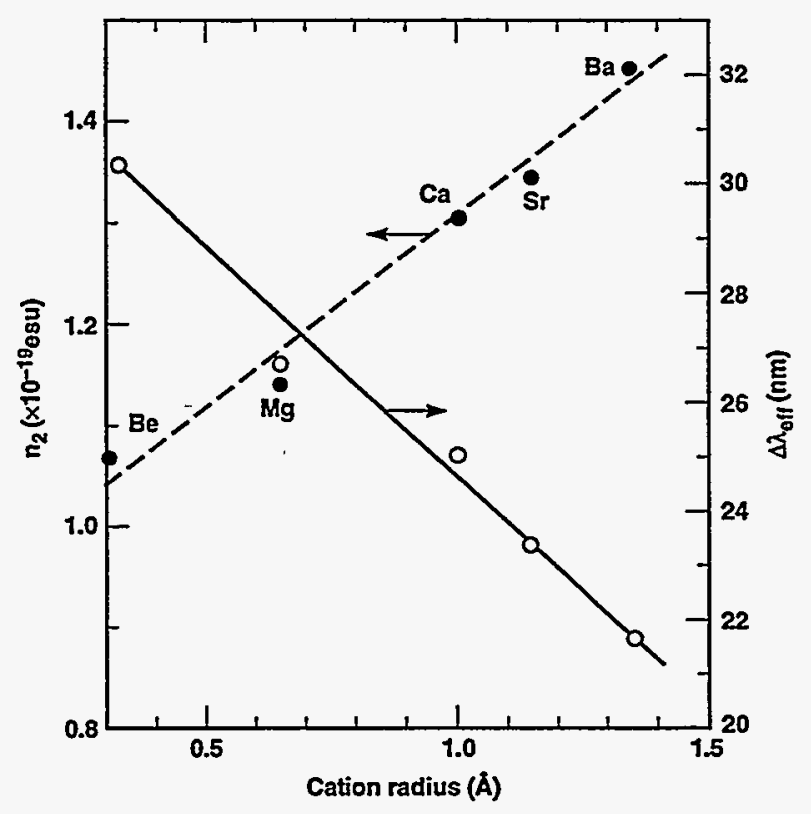

$40000585-11390601$

15 HCmem

Figure 7. Correlation of non-linear refractive index $\left(n_{2}\right)$ and emission bandwidth vs. cation radius for the group $I$ series $\mathrm{Be}, \mathrm{Mg}, \mathrm{Ca}, \mathrm{Sr}$ and $\mathrm{Ba} .{ }^{13 \mathrm{~b}}$

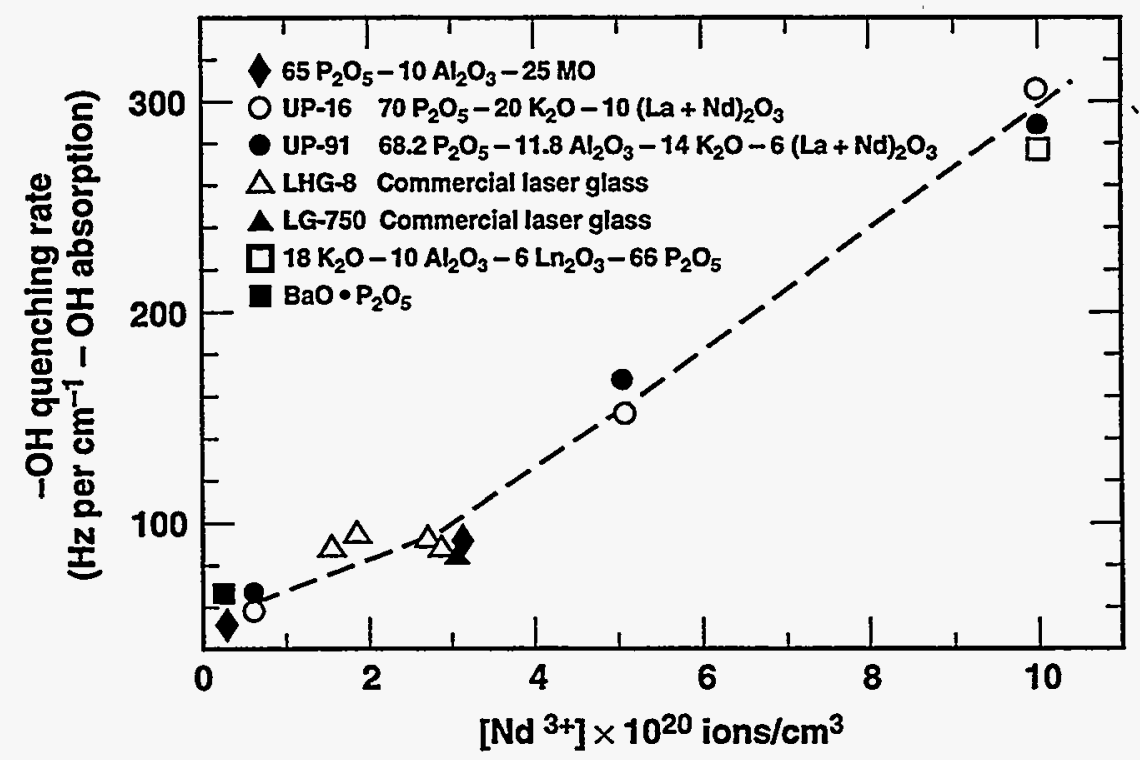

40-00-0596-1156pb01

15. $\mathrm{HC} / \mathrm{mom}$

Figure 8. Quenching rate due to -OH contamination for glasses with various Nd concentrations. The dashed line is a smooth curve drawn through the points. Sources: Toratani ${ }^{29}$, Stokowski et $\mathrm{al}^{4}$, Caird ${ }^{57}$, Jiang et $\mathrm{al}^{58}$, Zhuo et al ${ }^{59}$. 


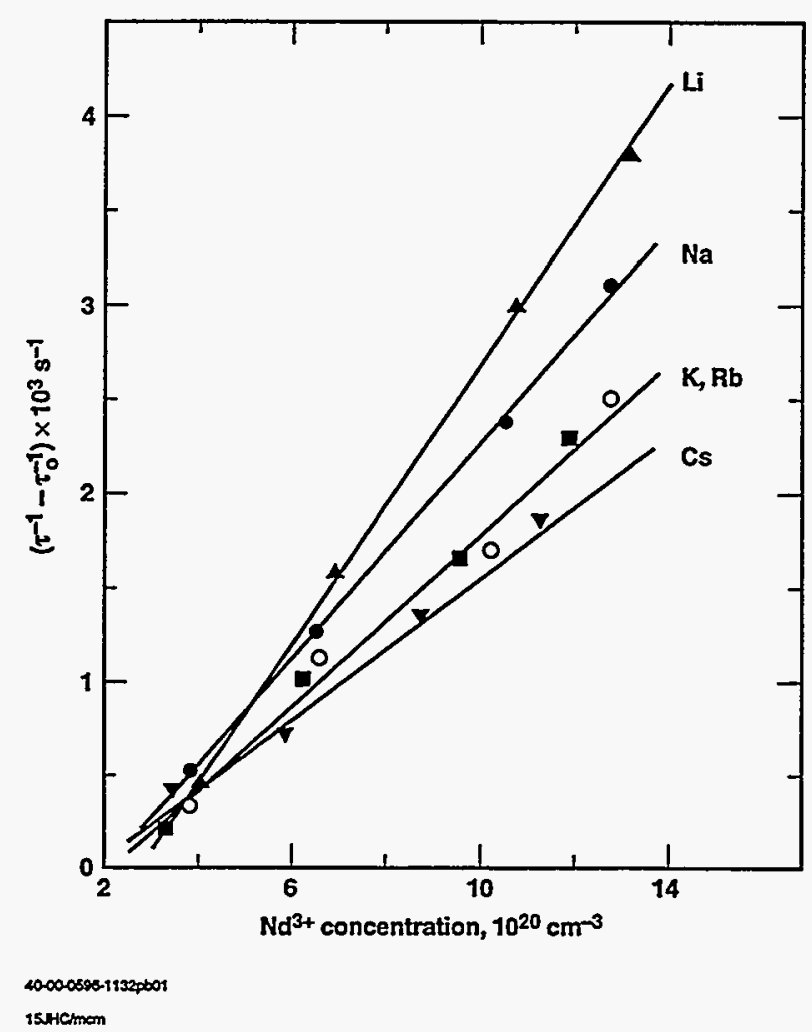

Figure 9. Effects of alkali oxide modifier on the concentration quenching rate measured in an ultraphosphate glass (from Lunter et. al. ${ }^{12}$ ).

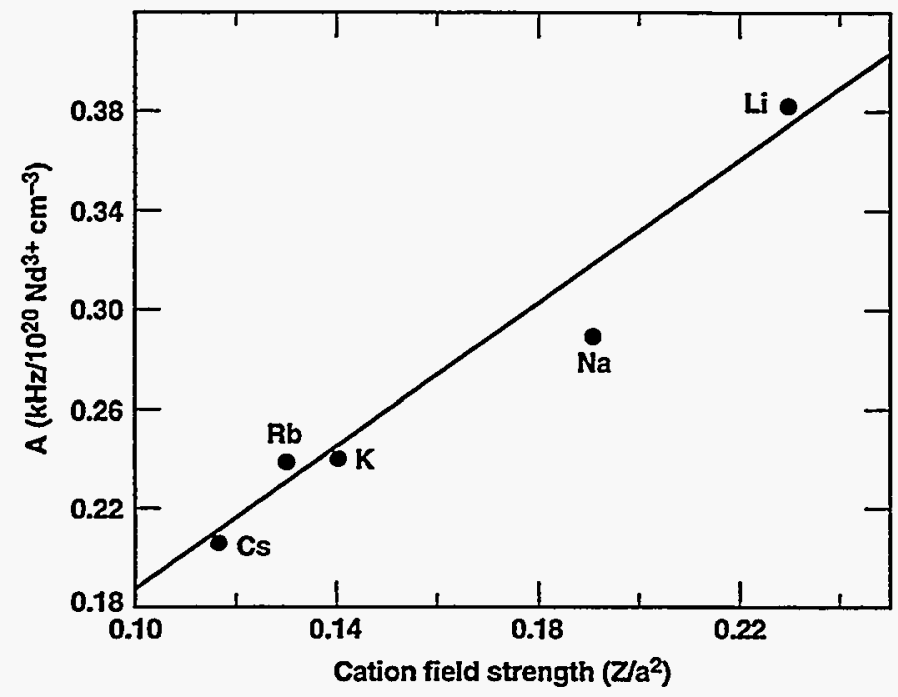

10-00-0596-1146pbot

$15 \mathrm{HC} / \mathrm{men}$

Figure 10. Correlation of quenching rate with modifier electric field strength (based on data from Figure 9) 
The effects of a systematic change in the group II modifiers on Nd concentration quenching is reported in the work by Byun et al. ${ }^{63}$ They use a Nd ${ }^{3+}$ doping range of 0.2 to $10 \times 10^{20}$ ions $/ \mathrm{cm}^{3}$ in two metaphosphate glasses: $45 \mathrm{RO}-2.5 \mathrm{Al}_{2} \mathrm{O}_{3}-52.5 \mathrm{P}_{2} \mathrm{O}_{5}$ and 35RO$10 \mathrm{Na}_{2} \mathrm{O}-2.5 \mathrm{Al}_{2} \mathrm{O}_{3}-52.5 \mathrm{P}_{2} \mathrm{O}_{5}$ where $\mathrm{R}=\mathrm{Mg}$, $\mathrm{Ca}$ or $\mathrm{Ba}$. The fluorescence lifetime data show a clear trend $\mathrm{Ba}<\mathrm{Ca}<\mathrm{Mg}$ in increased Nd self-quenching. This agrees with the trend observed for the group I oxides (see Fig. 8) in that the quenching rate increases with modifier electric field strength.

\subsection{Laser damage threshold and progress on eliminating inclusions and bubbles.}

The operating fluence and irradiance of the future ICF mega-joule scale lasers will be higher than any current laser system. Peak fluences in the laser glass will approach 18 to $20 \mathrm{~J} / \mathrm{cm}^{2}$ with a peak irradiance of about $5.0 \mathrm{GW} / \mathrm{cm}^{2}{ }^{64}$ To avoid any optical damage the laser glass must be free of defects, specifically any microscopic inclusions (either metallic or ceramic) left from the melting process. The most common inclusion source is metallic Pt inclusions from the Pt liners used in the melting system. ${ }^{40}$ Prior to $1986, \mathrm{Pt}$ inclusion damage represented the major source of damage in laser glass used for highpeak-power applications. However new processing methods effectively reduce the $\mathrm{Pt}$ inclusion concentration by more that 1000 -fold to less than 0.1 per liter. ${ }^{40-42}$ For example, $50 \%$ of the large laser slabs $\left(79 \times 45 \times 4 \mathrm{~cm}^{3} ; 14\right.$ liters of glass each) used on the new Beamlet laser at LLNL had no inclusions at all and the average for all the slabs produced was about 1 per slab. ${ }^{51}$ Similar results have been achieved for the several hundred replacement glass disks manufactured for the Nova and Phebus laser; each of those disks contained 7 liters of glass. ${ }^{40,65}$

Inclusions in the laser glass damage at about $2-5 \mathrm{~J} / \mathrm{cm}^{2}$ at the 1-10 pulse lengths typical of most HPP applications. ${ }^{66}$ Although very small to begin with, inclusion damage can grow with successive laser shots to several millimeters or even centimeters in size eventually making the laser glass unusable. Also large damage spots ( $>300 \mu \mathrm{m})$ in the laser glass can seed damage in other optics in the laser chain. ${ }^{32}$ In general, if the inclusions are small they can be tolerated as long as the optical damage they produce does not exceed $300 \mu \mathrm{m}$ in size. Inspection methods have been developed and put into production to scan each piece of laser glass with a high fluence laser beam and measure the size of any damage site after 100 shots at fluences between 7 to $14 \mathrm{~J} / \mathrm{cm}^{2}(8 \mathrm{~ns}){ }^{65}$

The new processing techniques for eliminating Pt inclusions rely on the intrinsic property of many phosphate glasses to dissolve Pt metal under oxidizing conditions. Izumitani et. al. ${ }^{39}$ have reported the use of gaseous $\mathrm{POCl}_{3}$ as an oxidizing additive and Campbell and co-workers at Hoya and Schott ${ }^{41,42}$ have reported the effects of $\mathrm{O}_{2}, \mathrm{Cl}_{2}, \mathrm{CCl}_{4}$ and $\mathrm{N}_{2} / \mathrm{O}_{2}$ mixtures. Model predictions of $\mathrm{Pt}$ inclusion dissolution rates agree well with results from glass melting tests. ${ }^{67}$

The effects of glass composition on platinum solubility have been reported to follow the trend: phosphate $>$ silica-phosphate $>$ fluorophosphate $>$ silicate. ${ }^{39}$ These results are based on solubility measurements using LHG-5 and LHG-8 (phosphates), HAP-3 (silicaphosphate), LHG-10 (fluorophosphate) and LSG-91H (silicate). In a similar study Hayden et. al. ${ }^{38}$ have examined the effects of the $\mathrm{Al}_{2} \mathrm{O}_{3}$ concentration in phosphate glasses on $\mathrm{Pt}$ 
solubility. They chose three commercial phosphate laser glasses (LG-770, LG-760 and APG-1) each having different $\mathrm{Al}_{2} \mathrm{O}_{3}$ content. The effects of alumina were studied because it is a common modifier added to improve thermal-mechanical properties and is often added to phosphate glasses used for HAP applications. These researchers report that the higher $\mathrm{Al}_{2} \mathrm{O}_{3}$ content reduces the $\mathrm{Pt}$ solubility. The effects of $\mathrm{Al}_{2} \mathrm{O}_{3}$ on Pt solubility tend to parallel those reported by Izumitani for $\mathrm{SiO}_{2}$ in Hoya HAP-3 glass. These observations suggest that large pieces of high-average-power glass may be more difficult than HPP glasses to manufacture $\mathrm{Pt}$ free.

Claims that other non-phosphate laser glasses (e.g. silicates) can be manufactured at reasonable sizes ( $\geq 1$ liter) free of $\mathrm{Pt}$ inclusions should be treated with some skepticism. This statement is not meant to question the integrity of the researchers reporting such claims but merely to point out the extreme difficulty of detecting the microscopic $\mathrm{Pt}$ inclusions $(\leq 10 \mu \mathrm{m})$ that commonly cause damage in laser glasses. Researchers at LLNL have found that the best way to insure laser glass is free of Pt inclusions is to raster-scan the entire glass volume at laser fluences significantly above the damage threshold of $\mathrm{Pt}$ inclusion. ${ }^{65}$ The one possible exception to this statement is for melting carried out in clay or other ceramic vessels. However, experience has shown that these melting methods typically trade the $\mathrm{Pt}$ inclusion problem for one with refractory inclusions and/or poor optical quality. ${ }^{40}$ The poor optical quality is due to the roughly 10 to $100 \mathrm{x}$ higher solubility of the refractory walls of ceramic materials in the molten glass.

If inclusions are eliminated from the bulk laser glass, the damage threshold is limited only by the quality of the surface finish. This is shown in Fig. 11 where the surface damage threshold is plotted versus pulse length for various laser glasses as well as fused silica. The pulse length dependence of the surface damage threshold for finely polished samples can be accurately represented by the empirical expression:

$$
D_{S}\left(J / \mathrm{cm}^{2}\right)=22 t_{p}^{0.4}
$$

where $t_{p}$ is the pulse length (ns). The surface damage threshold approximately follows the $t^{1 / 2}$ relationship predicted by a thermal diffusion heat transport model. For comparison the damage threshold reported by Gonzales and Milam ${ }^{66}$ for $\mathrm{Pt}$ inclusions is also shown in Fig. 11; it follows the approximate pulse length scaling relationships:

$$
\mathrm{D}_{\mathrm{Pt}}\left(\mathrm{J} / \mathrm{cm}^{2}\right)=2 \mathrm{t}_{\mathrm{P}}^{03} \text {. }
$$

Thus the presence of $\mathrm{Pt}$ inclusions reduces the operating limit of the laser glass by about 10-fold.

The success in eliminating Pt inclusions from phosphate glasses has induced one manufacturer (Hoya Corporation) to produce an updoped version (PSC-7) for use as a low loss, high damage threshold passive optical glass for HPP applications. ${ }^{68}$ PSC-7 has optical properties nearly identical to the common silicate optical glass, BK-7. 
The $\mathrm{Pt}$ that dissolves in the glass melt is ionic (presumably $\mathrm{Pt}^{4+}$ ). Ionic $\mathrm{Pt}$ absorbs in the near UV although the tail of the absorption band extends into the visible, giving noticeable absorption up to about $400 \mathrm{~nm}$. This can affect the energy strorage of the laser glass because the absorption blocks some of the flashlamp irradiation and reduces the pumping efficiency. The $400 \mathrm{~nm}$ absorption due to $\mathrm{Pt}^{4+}$ is generally specified not to exceed $0.25 \mathrm{~cm}^{-1}$; 51 this corresponds to a Pt concentration of less than about $150 \mathrm{ppm}^{40}$ For heavily doped rods or slabs (i.e. $\mathrm{Nd}^{3+}>1 \times 10^{20} \mathrm{~cm}^{3}$ ) the effect of the ionic $\mathrm{Pt}$ absorption is small as long as the absorption at $400 \mathrm{~nm}$ does not exceed a value of about $0.25 \mathrm{~cm}^{-1}$. Kelly and co-workers ${ }^{69}$ however, have analyzed the effect of ionic $\mathrm{Pt}$ absorption on the flashlamp pumping of lightly doped rods. They estimate that an ionic $\mathrm{Pt}$ absorption value at or near $0.25 \mathrm{~cm}^{-1}$ can reduce the pumping efficiency by $10-15 \%$ for $9.9 \mathrm{~cm}$ diameter laser glass rods doped with about $0.55 \mathrm{wt} \% \mathrm{Nd}$.

Elimination or reduction in the size of bubbles in laser glasses is important for two reasons: first to reduce the amount of light loss due to the obscuration and scattering caused by the bubbles and second to keep the size below a certain value that may induce non-linear growth of intensity noise. ${ }^{32}$ Most laser glass specifications (for ICF lasers) require the total obscuration loss not to exceed $10^{-5}$ of the beam aperture per slab. In general, bubbles have not been a significant problem for laser glass. For example, 95\% of all the large (14 liter) laser slabs used on the Beamlet laser had no bubbles at all. ${ }^{51}$ Similar results were observed for the 7-liter Nova and Phebus laser glass disks.

\subsection{Estimating $\mathrm{dn} / \mathrm{dT}$ from laser glass compositions.}

The temperature coefficient of the refractive index ( $\mathrm{dn} / \mathrm{dT}$ ) is defined by eqn (16). Izumitani and Toratani ${ }^{70}$ and Toratani ${ }^{29}$ report a method for calculating $\mathrm{dn} / \mathrm{dT}$ based on an additivity relationship for estimating the temperature coefficient of the electronic polarizability, $\phi$ :

$$
\phi=\Sigma \phi_{i} X_{i}
$$

where $\phi_{i}$ is the additive contribution from glass component $i$ and $X_{i}$ is the component mole fraction. Table 2 lists values of $\phi_{i}$ for various common oxides in silicate ${ }^{70}$ and phosphate glasses ${ }^{29}$. The $\phi_{\mathrm{i}}$ values for $\mathrm{SiO}_{2}, \mathrm{Li}_{2} \mathrm{O}, \mathrm{MgO}$ and $\mathrm{CaO}$ in phosphate glasses are estimated values by this reviewer. We have used the data in Table 2 for estimating $\mathrm{dn} / \mathrm{dT}$ for a number of laser glasses and, in general, find good agreement with measured values (see Table 2).

\subsection{Edge cladding development}

Edge claddings are used to suppress parasitic oscillations of amplified spontaneous emission (ASE) while pumping large pieces of laser glass. ${ }^{18,19}$ Edge cladding consists of a refractive-index-matched glass that is doped (usually with $\mathrm{Cu}^{+2}$ ) to absorb at the laser wavelength. The cladding is bonded to the edges of the laser glass disks or slabs and absorbs the ASE, thereby preventing parasitics from developing. Adhesively-bonded edge claddings have been developed and are now widely in the US and Europe. ${ }^{71}$ This new edge cladding process replaces the difficult and costly high temperature molten glass and sintered frit-glass processes used in the late 70's and early 80's. In addition the 
adhesively bonded cladding, because it is applied at room temperature, is free of residual strain and optical distortion commonly produced near the edges of the glass fabricated using high temperature cladding processes. The adhesive that is used is a two part optical epoxy that, after curing, has a $\mathrm{Tg}$ slightly above room temperature. The refractive index match to the laser glass is about \pm 0.003 and can be tuned somewhat by changing the ratio of two epoxide resins; one of the resins is a high index aromatic based material while the other is a lower index epoxide largely comprised of straight chain hydrocarbons. ${ }^{71}$

Table 2. Additivity factors $\phi_{\mathrm{i}}\left(10^{-6} / \mathrm{K}\right)$ for estimating the temperature coefficient of electronic polarizability from the glass composition (from ref. 29 and 70).

\begin{tabular}{|c|c|c|c|c|c|}
\hline \multirow[b]{2}{*}{ Component } & \multicolumn{2}{|c|}{$\phi_{i}\left(10^{-6} / \mathrm{K}\right)$} & \multicolumn{3}{|c|}{$\mathrm{dn} / \mathrm{dT}\left(10^{-6} \mathrm{~K}\right)$} \\
\hline & Silicates & Phosphates & Glass & Predicted & Measured \\
\hline $\mathrm{SiO}_{2}$ & 17.4 & 20 (est.) & LHG-8 & -4.75 & -5.3 \\
\hline $\mathrm{PO}_{0.5}$ & - & 20 & LHG-80 & -3.6 & -3.8 \\
\hline $\mathrm{BO}_{1.5}$ & 13.8 & 16 & LG-750 & -6.0 & -6.8 \\
\hline $\mathrm{AlO}_{1.5}$ & 22.2 & 26 & LG-760 & -4.9 & -5.1 \\
\hline $\mathrm{LiO}_{0.5}$ & 一 & 36 (est.) & HAP-3 & 1.0 & 1.9 \\
\hline $\mathrm{NaO}_{0.5}$ & 50.0 & 44 & APG-1 & 1.3 & 1.2 \\
\hline $\mathrm{KO}_{0.5}$ & 43.9 & 45 & & & \\
\hline $\mathrm{MgO}$ & - & 45 (est.) & & & \\
\hline $\mathrm{CaO}$ & 42.0 & 42 (est.) & & & \\
\hline $\mathrm{BaO}$ & 36.1 & 35 & & & \\
\hline $\mathrm{PbO}$ & 50.2 & 47 & & & \\
\hline $\mathrm{TiO}_{2}$ & 19.3 & 15 & & & \\
\hline $\mathrm{ZnO}$ & 39.4 & - & & & \\
\hline
\end{tabular}

\subsection{Compilation of HPP laser glass properties}

The key properties of several commercial HPP laser glasses are summarized in Table 3. Although there are other HPP glasses that are being manufactured, the ones listed in Table 3 (with the exception of LG-770) are the most widely used glasses in the US, Japan and Europe. Table 4 lists the major large Nd-glass HPP laser systems in the western world and the type and maximum size of laser glass installed.

The largest pieces of laser glass produced to date are the slabs installed on the LLNL Beamlet laser (Fig 12). ${ }^{51}$ Beamlet is a prototype of the design of the next generation nuclear fusion research laser. ${ }^{72}$ These lasers will consist of about 200 identical beamlines or "beamlets" that are designed to collectively produce output energies of 1.5 to $2 \mathrm{MJ}$ at the third harmonic (351nm) with peak powers of about $5.0 \times 10^{14} \mathrm{~W} \cdot{ }^{73,74}$

The newest glass to join the list for use on HPP fusion lasers is LG-770. Compared to LG-750, LG-770 has a lower non-linear index, improved laser and thermal-mechanical 
Table 3: Properties of commercially available HPP glasses in common use on ICF lasers.

\begin{tabular}{|c|c|c|c|c|c|c|}
\hline \multicolumn{2}{|l|}{ Glass Manufacturer } & \multicolumn{2}{|c|}{ Hoya } & \multicolumn{2}{|c|}{ Schott } & Kigre \\
\hline Glass Properties & Symbol & LHG-80 & LHG-8 & LG-770 & LG-750 & Q88 \\
\hline $\begin{array}{l}\text { Optical } \\
\text { refractive index } \\
\text { @ } 587.3 \mathrm{~nm} \\
\text { @ } 1053 \mathrm{~nm} \\
\text { non-linear refractive index } \\
\quad\left(10^{-13} \mathrm{esu}\right) \\
\quad\left(10^{-20} \mathrm{~m}^{2} / \mathrm{W}\right) \\
\text { Abbe number } \\
\text { Temp-coeff. refract. index }\left(10^{-6} / \mathrm{K}\right) \\
\text { Temp-coeff. optical path }\left(10^{-6} / \mathrm{K}\right)\end{array}$ & $\begin{array}{c}\mathrm{n}_{\mathrm{d}} \\
\mathrm{n}_{1} \\
\\
\mathrm{n}_{2} \\
\gamma \\
v \\
\mathrm{dn} / \mathrm{dT} \\
\delta \\
\end{array}$ & \begin{tabular}{c|}
1.54291 \\
1.53289 \\
\\
1.24 \\
3.36 \\
64.7 \\
-3.8 \\
1.8 \\
\end{tabular} & $\begin{array}{c}1.52962 \\
1.52005 \\
1.12 \\
3.08 \\
66.5 \\
-5.3 \\
0.6 \\
\end{array}$ & $\begin{array}{c}1.50675 \\
1.49908 \\
\\
1.00 \\
2.78 \\
68.5 \\
-5.5^{\mathrm{b}} \\
1.3^{\mathrm{b}} \\
\end{array}$ & $\begin{array}{r}1.526 \\
1.516 \\
\\
1.08 \\
2.98 \\
68.2 \\
-5.1 \\
0.8 \\
\end{array}$ & $\begin{array}{c}1.5449 \\
1.5363 \\
\\
1.14 \\
3.11 \\
64.8 \\
-0.5 \\
2.7 \\
\end{array}$ \\
\hline $\begin{array}{l}\text { Laser } \\
\text { emission cross-section }\left(10^{-20} \mathrm{~cm}^{2}\right) \\
\text { saturation fluence }\left(\mathrm{J} / \mathrm{cm}^{2}\right) \\
\text { radiative lifetime (zero-Nd) }(\mu \mathrm{s}) \\
\text { Judd-Ofelt radiative lifetime }(\mu \mathrm{s}) \\
\text { Judd-Ofelt parameters }\left(10^{-20} \mathrm{~cm}^{2}\right) \\
\\
\text { emission band width }(\mathrm{nm}) \\
\text { conc. quenching factor }\left(\mathrm{cm}^{-3}\right)^{\mathrm{c}} \\
\text { fluorescense peak }(\mathrm{nm})\end{array}$ & $\begin{array}{c}\sigma_{\mathrm{em}} \\
\mathrm{F}_{\mathrm{sat}} \\
\tau_{\mathrm{o}} \\
\tau_{\mathrm{r}} \\
\Omega_{2} \\
\Omega_{4} \\
\Omega_{6} \\
\Delta \lambda_{\text {eff }} \\
Q \\
\lambda_{\mathrm{L}}\end{array}$ & $\begin{array}{c}4.2 \\
4.5 \\
337 \\
327 \\
- \\
- \\
- \\
23.9 \\
10.1 \\
1054\end{array}$ & $\begin{array}{c}3.6 \\
5.3 \\
365 \\
351 \\
4.4 \\
5.1 \\
5.6 \\
26.5 \\
- \\
1054\end{array}$ & $\begin{array}{c}3.9 \\
4.8 \\
364 \\
349 \\
4.3 \\
5.0 \\
5.6 \\
25.4 \\
9.3^{\text {d }} \\
1053\end{array}$ & $\begin{array}{c}3.7 \\
5.1 \\
383 \\
367 \\
4.6 \\
4.8 \\
5.6 \\
25.3 \\
7.4 \\
1053.5\end{array}$ & $\begin{array}{c}4.0 \\
4.7 \\
326 \\
326 \\
3.3 \\
5.1 \\
5.6 \\
21.9 \\
6.6 \\
1054\end{array}$ \\
\hline $\begin{array}{l}\text { Thermal } \\
\text { thermal conduct., }(\mathrm{W} / \mathrm{mK}) \\
\text { thermal diffusivity }\left(10^{-7} \mathrm{~m}^{2} / \mathrm{s}\right) \\
\text { specific heat, }(\mathrm{J} / \mathrm{gK}) \\
\text { Coeff. thermal expan. } *\left(10^{-7} / \mathrm{K}\right) \\
\text { Glass transition temp }\left({ }^{\circ} \mathrm{C}\right)\end{array}$ & $\begin{array}{l}\mathrm{k} \\
\alpha \\
\mathrm{C}_{\mathrm{p}} \\
\alpha_{\mathrm{e}} \\
\mathrm{T}_{\mathrm{p}}\end{array}$ & $\begin{array}{c}0.59 \\
3.2 \\
0.63 \\
130 \\
402\end{array}$ & $\begin{array}{c}0.58 \\
2.7 \\
0.75 \\
127 \\
485\end{array}$ & $\begin{array}{c}0.57 \\
3.1 \\
0.71 \\
135 \\
460\end{array}$ & $\begin{array}{c}0.60 \\
2.9 \\
0.72 \\
132 \\
450\end{array}$ & $\begin{array}{c}0.84 \\
- \\
0.81 \\
104 \\
367\end{array}$ \\
\hline $\begin{array}{l}\text { Mechanical } \\
\text { density }\left(\mathrm{g} / \mathrm{cm}^{3}\right) \\
\text { Poisson's ratio } \\
\text { Fracture toughness }\left(\mathrm{MPa} \mathrm{m}^{0.5}\right) \\
\text { Hardness }(\mathrm{GPa}) \\
\text { Young's modulus }(\mathrm{GPa}) \\
\text { Stress optic coeff. }(\mathrm{Pa}) \\
\end{array}$ & $\begin{array}{c}\rho \\
\mu \\
\mathrm{K}_{1 \mathrm{C}} \\
\mathrm{H} \\
\mathrm{E} \\
\Delta \mathrm{B} \\
\end{array}$ & $\begin{array}{l}2.92 \\
0.27 \\
0.46 \\
3.35 \\
50.1 \\
1.77\end{array}$ & $\begin{array}{c}2.83 \\
0.26 \\
- \\
3.43 \\
68.1 \\
1.93 \\
\end{array}$ & $\begin{array}{r}2.59 \\
0.25 \\
0.6 \\
3.58 \\
68.1 \\
-\end{array}$ & $\begin{array}{c}2.83 \\
0.26 \\
0.4 \\
2.85 \\
50.1 \\
1.80\end{array}$ & $\begin{array}{c}2.71 \\
0.24 \\
- \\
- \\
70.1 \\
2.07 \\
\end{array}$ \\
\hline
\end{tabular}

$* 20-300^{\circ} \mathrm{C}$.

a measured by LLNL

b estimated

c $Q$ defined by quadratic relationship (Eqn. 8)

d ref. 86 
Table 4: Summary of Laser Glass Type and Maximum Sizes Installed on Operating and Planned ICF Laser Systems

\begin{tabular}{|c|c|c|c|c|}
\hline & & Largest Glass Size & finished) & \\
\hline Laser System & Glass & $\begin{array}{c}\text { Dimensions } \\
\left(\mathrm{cm}^{3}\right)\end{array}$ & $\begin{array}{l}\text { Volume } \\
\text { (iter) }\end{array}$ & $\begin{array}{l}\text { Nd-doping } \\
\left(\times 10^{20} / \mathrm{cm}^{3}\right)\end{array}$ \\
\hline I. Operatio & & & & \\
\hline Nova ${ }^{a}$ & LG-750 & $62.9 \times 34.2 \times 4.3$ & 7 & 2.0 \\
\hline & LHG-8 & $48 \times 45.4 \times 4.3$ & 7 & 3.0 \\
\hline & $\mathrm{Q}-88$ & $30.9 \times 16.4 \times 3^{f}$ & 1.2 & 2.0 \\
\hline Beamlet $^{a}$ & LG-750 & $78.8 \times 44.8 \times 4$ & 14 & 3.4 \\
\hline Omega & LHG-8 & $44.8 \times 27.6 \times 3$ & 2.0 & 3.0 \\
\hline Upgrade $^{b}$ & LHG-8 & $9.0 \phi \times 37.0^{e}$ & 2.3 & 2.0 \\
\hline Phebus ${ }^{c}$ & LG-750 & $63 \times 34 \times 4.3$ & 7 & 2.0 \\
\hline & LHG-8 & $48 \times 45.4 \times 4.3$ & 7 & 3.0 \\
\hline & Q-88 & $30.9 \times 16.4 \times 3^{f}$ & 1.2 & 2.0 \\
\hline Gekko XII & LHG-80\&-8 & $40.0 \times 21.4 \times 3.2^{2}$ & & 2.0 \\
\hline & LHG-80\&-8 & $50.0 \phi \times 37^{e}$ & 0.7 & 0.6 \\
\hline
\end{tabular}

\section{Planned}

"Petawatt"(1997) LHG-80 $69.4 \times 38 \times 4.5^{\text {f }}$

LIL (2002) $)^{c}$ LG-770+LHG-8 $80.2 \times 45.7 \times 4.1 \quad 15.0 \quad 3.6-4.0$

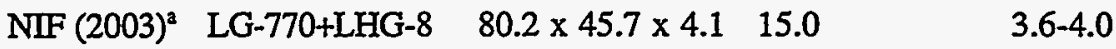

LMJ $(2008)^{c}$ LG-770+LHG-8 $80.2 \times 45.7 \times 4.1 \quad 15.0 \quad 3.6-4.0$

a LLNL, USA; 'bLE, USA; 'CEA, France; 'Osaka Univ., Japan; rod;

$\mathrm{f}=$ molten glass cladding; all others are epoxy bonded 
properties and also some improved characteristics important for high volume

manufacturing. LG-770 and LHG-8 are the glasses chosen for use on the next generation, mega-joule scale fusion lasers to be built in the US and France(see Table 4).

Regrettably this reviewer was unable to find a comparable set of data to that given in Table 3 and 4 for the glasses manufactured and in use on the laser facilities in Russia and China. Gan ${ }^{13}$ gives some data on the Chinese $\mathrm{N}_{0}$ (silicate) and $\mathrm{N}_{2}$ (phosphate) series of glasses; however much of this information is dated (late 1970's and early 80's). The data undoubtedly exists and perhaps our foreign colleagues can provide this in a future review.

\section{PROGRESS ON HAP LASER GLASSES.}

Much of the development and related work on HPP glasses that was reviewed in section 3. has application for HAP glasses. However, HAP glasses must also have superior thermal-physical properties to satisfy the high thermal loading experienced during operation. Consequently, much of the compositional work on HAP glasses has focused on maximizing the glass thermal shock resistance (Eq. 17). The general development approach has been the following: 1) improve the intrinsic thermal-physical properties of the glass by appropriate compositional changes or 2) modify the glass composition such that it can be post-processed to improve the strength (e.g. ion exchange) or 3) do both.

Payne and co-workers ${ }^{26}$ at Schott Glass Technologies have taken the compositional route and report the development of a new high average power laser glass APG- $t$ (where " $t$ " means test glass). This glass can withstand 2.3 times greater thermal loading without fracture compared to APG-1. The properties of this glass are summarized in Table 5. Recall that APG-1 was developed during the late 1980 's by Hayden et al. ${ }^{75}$

In an earlier compositional study, workers at Hoya Corporation developed the silicaphosphate glass $\mathrm{HAP}-3^{76,77}$ having the base composition $60 \mathrm{P}_{2} \mathrm{O}_{5}-15 \mathrm{SiO}_{2}-10 \mathrm{Al}_{2} \mathrm{O}_{3}$ $13 \mathrm{Li}_{2} \mathrm{O}-2 \mathrm{Nd}_{2} \mathrm{O}_{3}{ }^{29}$ This glass was later improved to the present HAP-4. HAP-4 can be further strengthened by a post treatment process involving ion-exchange of the $\mathrm{Li}$ for larger cations $\left(\mathrm{K}^{+}, \mathrm{Na}^{+}\right){ }^{78}$ This exchange process generates a compressive layer at the surface.

Researchers at Kigre, Inc. have been involved in compositional development of HAP glasses for a number of years, they currently produce ion-exchange strengthen $\mathrm{Er}^{3+}, \mathrm{Yb}^{3+}$ and $\mathrm{Nd}^{3+}$ doped phosphate glasses. ${ }^{79}$ Early work by Cerqua et $\mathrm{al}^{34,80}$ in collaboration with researchers at Kigre showed that Q-89 could be ion-exchanged strengthened. Q-89 is an $\mathrm{Li}_{2} \mathrm{O}$ containing $\mathrm{BaO}-\mathrm{Al}_{2} \mathrm{O}_{3}-\mathrm{P}_{2} \mathrm{O}_{5}$ metaphosphate glass and a forerunner of the current $\mathrm{QX}$ glasses. The performance of the new $\mathrm{Yb}$-doped glass $(\mathrm{QX}-\mathrm{Yb})$ has recently been reported by Griebner et al. ${ }^{79 b}$

Jiang et. al. ${ }^{58}$ at the Shanghai Institute have developed an average power glass (VLPG) with properties similar to HAP-4 and APG-1. They correlate the thermal expansion coefficient with cation electric field strength for $\mathrm{K}, \mathrm{Na}, \mathrm{Li}, \mathrm{Ba}, \mathrm{Sr}$ and $\mathrm{Ca}$ in a systematic compositional series that also includes changes in the $\mathrm{Al}_{2} \mathrm{O}_{3}$ content. 


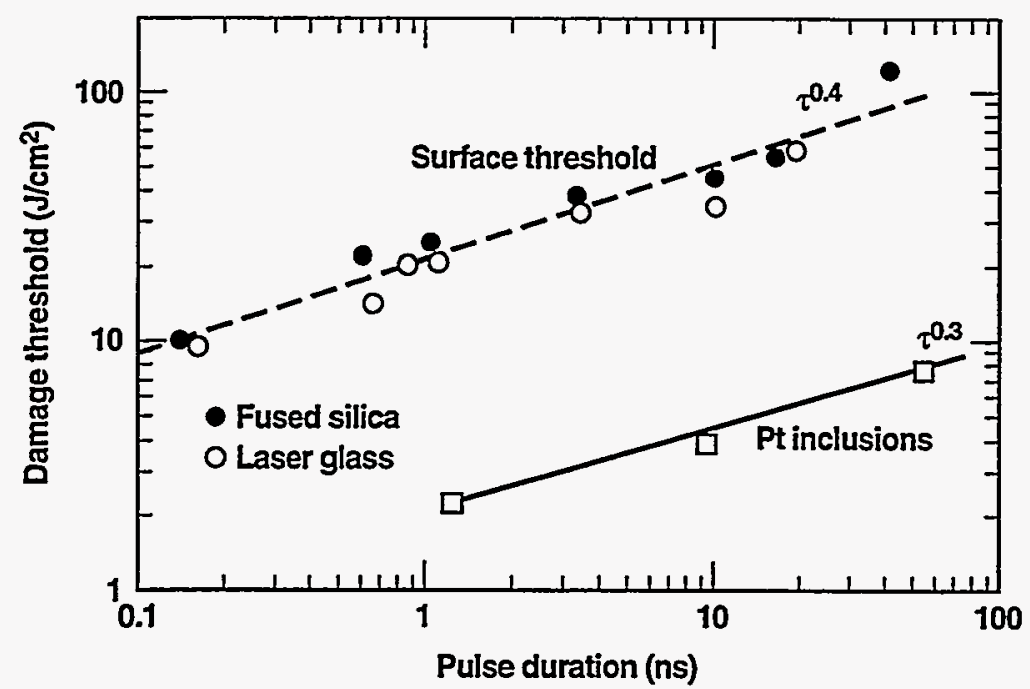

40-00-0596-1133pb01

$15 \mathrm{JHC} / \mathrm{mom}$

Figure 11. Measured surface damage threshold for various polished laser glasses and fused silica vs. pulse length. ${ }^{64}$ Also shown are bulk laser glass damage thresholds due to $\mathrm{Pt}$ inclusions as reported by Gonzales and Milam. ${ }^{119}$

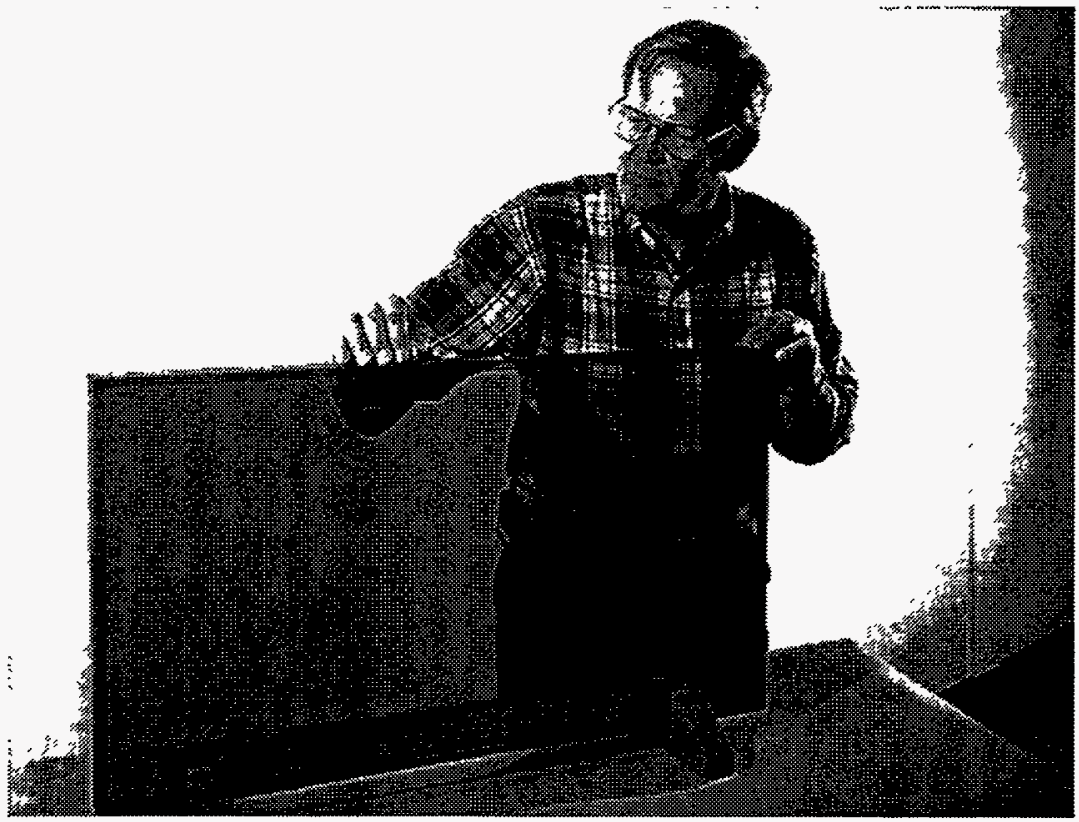

70-50-0383-07160502

Figure 12. Photograph of a finished (and clad) laser slab of LG-750 that is one of 18 in use on the LLNL Beamlet laser. This is the largest slab size that can be manufactured with existing technology $\left(78.8 \times 44.8 \times 4 \mathrm{~cm}^{3}\right)$. 
Several new methods have been developed for evaluating either the glass strength or maximum thermal loading of HAP glasses. Perhaps the most important are those developed by Marion that are based on a fundamental understanding of the fracture mechanics of the glass. ${ }^{14-16}$ Other methods have been reported by Russian researchers. ${ }^{81,82}$ Table 5 is a compilation of properties for several common commercially available HAP glasses including the newly developed APG-t glass. ${ }^{26}$

Table 5: Properties of commercially available HAP glasses.

\begin{tabular}{|c|c|c|c|c|c|}
\hline Glass Manufacture & & Kigre & & & Hoya \\
\hline Glass Properties & Symbol & QX-Nd & APG-1 & APG-t & HAP-4 \\
\hline $\begin{array}{l}\text { Optical } \\
\text { refractive index } \\
\text { @ } 587.3 \mathrm{~nm} \\
\text { @ } 1053 \mathrm{~nm} \\
\text { non-linear refractive index } \\
\quad\left(10^{-13} \mathrm{esu}\right) \\
\quad\left(10^{-20} \mathrm{~m}^{2} / \mathrm{W}\right) \\
\text { Abbe number } \\
\text { Temp-coeff. refract. index }\left(10^{-6} / \mathrm{K}\right) \\
\text { Temp-coeff. optical path }\left(10^{-6} / \mathrm{K}\right)\end{array}$ & $\begin{array}{c}\mathrm{n}_{\mathrm{d}} \\
\mathrm{n}_{\mathrm{l}} \\
\\
\mathrm{n}_{2} \\
\gamma \\
v \\
\mathrm{dn} / \mathrm{dT} \\
\delta\end{array}$ & $\begin{array}{c}1.538 \\
1.53 \\
\\
1.17 \\
3.2 \\
66.0 \\
1.0 \\
4.8 \\
\end{array}$ & $\begin{array}{l}1.13 \\
3.1 \\
67.7 \\
1.2 \\
5.2 \\
\end{array}$ & $\begin{array}{c}1.02 \\
2.85 \\
67.8 \\
4.0 \\
7.6\end{array}$ & $\begin{array}{c}1.21 \\
3.32 \\
64.6 \\
1.8 \\
5.7 \\
\end{array}$ \\
\hline $\begin{array}{l}\text { Laser } \\
\text { emission cross-section }\left(10^{-20} \mathrm{~cm}^{2}\right) \\
\text { Saturation Fluence }\left(\mathrm{J} / \mathrm{cm}^{2}\right) \\
\text { radiative lifetime (zero-Nd) }(\mu \mathrm{s}) \\
\text { Judd-Ofelt radiative lifetime }(\mu \mathrm{s}) \\
\text { emission band width }(\mathrm{nm}) \\
\text { conc. quenching factor }\left(\mathrm{cm}^{-3}\right)^{\mathrm{b}} \\
\text { fluorescence peak }(\mathrm{nm})\end{array}$ & $\begin{array}{c}\sigma_{\text {em }} \\
\mathrm{F}_{\text {sat }} \\
\tau_{0} \\
\tau_{\mathrm{r}} \\
\Delta \lambda_{\text {eff }} \\
Q \\
\lambda_{\mathrm{L}} \\
\end{array}$ & $\begin{array}{c}3.34 \\
5.6 \\
353 \\
- \\
27.6 \\
- \\
1054 \\
\end{array}$ & $\begin{array}{c}3.35 \\
5.6 \\
385 \\
361 \\
26.7 \\
16.7 \\
1053.9 \\
\end{array}$ & $\begin{array}{c}2.39 \\
7.9 \\
46.4 \\
456 \\
31.5 \\
10.6 \\
1054.6 \\
\end{array}$ & $\begin{array}{c}3.6 \\
5.3 \\
350^{\mathrm{a}} \\
- \\
27.0 \\
- \\
1054 \\
\end{array}$ \\
\hline $\begin{array}{l}\text { Thermal } \\
\text { thermal conduct., }(\mathrm{W} / \mathrm{mK}) \\
\text { thermal diffusivity }\left(10^{-7} \mathrm{~m}^{2} / \mathrm{s}\right) \\
\text { specific heat, }(\mathrm{J} / \mathrm{gK}) \\
\text { Coeff. thermal expan. }{ }^{*}\left(10^{-7} / \mathrm{K}\right) \\
\text { Glass transition temp }\left({ }^{\circ} \mathrm{C}\right)\end{array}$ & $\begin{array}{l}k \\
\alpha \\
C_{p} \\
\alpha_{e} \\
T_{g}\end{array}$ & $\begin{array}{c}0.85 \\
- \\
- \\
84 \\
506 \\
\end{array}$ & $\begin{array}{c}0.83 \\
3.74 \\
0.84 \\
76 \\
450 \\
\end{array}$ & $\begin{array}{c}0.86 \\
- \\
- \\
64 \\
549 \\
\end{array}$ & $\begin{array}{c}1.02 \\
5.2 \\
0.71 \\
72 \\
486 \\
\end{array}$ \\
\hline $\begin{array}{l}\text { Mechanical } \\
\text { density }\left(\mathrm{g} / \mathrm{cm}^{3}\right) \\
\text { Poisson's ratio } \\
\text { Fracture toughness }\left(\mathrm{MPa} \mathrm{m}^{0.5}\right) \\
\text { Hardness }(\mathrm{GPa}) \\
\text { Young's modulus }(\mathrm{GPa}) \\
\text { Stress optic coeff. }(\mathrm{Pa}) \\
\end{array}$ & $\begin{array}{c}\rho \\
\mu \\
\mathrm{K}_{1 \mathrm{C}} \\
\mathrm{H} \\
\mathrm{E} \\
\Delta \mathrm{B} \\
\end{array}$ & $\begin{array}{c}2.66 \\
0.24 \\
- \\
- \\
71 \\
2.1 \\
\end{array}$ & $\begin{array}{c}2.64 \\
0.24 \\
0.60 \\
3.09 \\
71 \\
2.2 \\
\end{array}$ & $\begin{array}{c}2.56 \\
0.24 \\
0.80 \\
- \\
64 \\
-\end{array}$ & $\begin{array}{c}2.70 \\
0.24 \\
0.83 \\
4.7 \\
70 \\
2.4 \\
\end{array}$ \\
\hline
\end{tabular}

$* 20-300^{\circ} \mathrm{C}$

a lifetime at $3.2 \times 10^{20} \mathrm{Nd}^{3+} / \mathrm{cm}^{3}$

b $Q$ define by linear relationship: $\tau_{\mathrm{em}}=\tau_{\mathrm{o}}(1-[\mathrm{Nd}] / \mathrm{Q})$; (see ref. 26$)$ 


\section{ADVANCED MANUFACTURING DEVELOPMENT}

HPP glass process development is being driven by the needs of the planned ICF National Ignition Facility (NIF) and Laser Mega-joule (LMJ) projects. ${ }^{73,74}$ These advanced lasers use a compact amplifier design called the "multi-segment amplifier" (MSA). ${ }^{18,19}$ The MSA consists of a stacked-array of rectangular laser glass plates inside a flashlamp pumped cavity. By using square apertures (i.e. square beams) it is possible to tightly pack the individual laser glass amplifiers into a compact matrix and thereby greatly reduce the size and cost of the system. Each of the laser glass slabs is about $790 \times 450 \times 44 \mathrm{~mm}^{3}$. Approximately $4000-5000$ slabs will be needed for each megajoule-scale laser; this represents a volume of $60-70 \mathrm{~m}^{3}$ (150 to 200 tonne) of high optical quality glass.

To meet the requirements of the future mega-joule size lasers, advanced laser glass manufacturing methods are being developed that would enable laser glass to be continuously produced at the rate of about one thousand glass slabs per year. This represents more than a 10 to 100 -fold improvement in the scale of the present manufacturing technology while meeting the same high optical quality requirements.

The glasses made for the existing large ICF laser systems (e.g. Nova [LLNL], Phebus [CEA], Beamlet [LLNL] and Omega [Univ. of Rochester]) were all manufactured using a one-at-a-time, discontinuous melting process. In the final two sections of this review, the current manufacturing method is compared and contrasted with the advanced melting processes now under development.

\subsection{Current technology: Discontinuous melting process}

In the first step of the discontinuous process (Fig. 13), a cullet glass is made by melting the raw starting materials. The cullet glass is usually melted in a relatively inert ceramic refractory crucible, and a bubbling gas is often added to remove unwanted volatile products, particularly water. The cullet melt is cast and then broken into smaller pieces. The cullet is generally full of bubbles, striae, and possibly some small particles of undissolved starting material.

The glass produced from the cullet melt is used in the final melting step which is conducted in large platinum crucibles. During this second melt step, the glass is homogenized to provide the striae-free, high optical quality glass necessary for laser applications. This homogenizing process involves two stages. ${ }^{83}$ The first is a refining or "fining" process conducted at high temperatures where the viscosity of the glass is low, allowing bubbles to rise to the surface. The second stage is a stiring process which is generally conducted at temperatures lower than either the melting or the refining stages. The continuous mixing thoroughly distributes all components within the glass melt, eliminating striae and thus ensuring uniformity of the refractive index over the entire casting. Finally, the melt is cooled to a temperature such that the viscosity of the glass is proper for casting into a mold of the appropriate size and shape. After casting, the glass undergoes a coarse annealing step, is inspected for inclusions and striae, and then is fine annealed to remove residual thermal stresses due to the forming process. 


\subsection{Advanced technology: continuous melting process}

In contrast to the discontinuous process, the advanced glass melting method will continuously produce large rectangular plates of laser glass at a rate that could exceed 20 per day. A continuous melting system for optical glass is generally divided into four main processing zones ${ }^{84,85}$ (Fig 13): (1) melting, (2) conditioning and refining, (3) homogenization and (4) forming. These regions are interconnected allowing for the continuous flow of glass from one zone to the next. The glass is cast as one continuous "strip" during the forming process; this strip is then cut to the desired length once it has been coarse annealed. Unlike the discontinuous process, the raw material will feed directly to the melter, eliminating the need to make a cullet melt.

Significant progress has been made in developing the continuous processing method for production of laser glass. Hoya Corporation (Fremont, $\mathrm{Ca}$.) has designed, built and tested a sub-scale melter that has melted and formed laser glass into a continuous strip with a cross-section of $28 \times 240 \mathrm{~mm}^{2}$ (see Fig 14). This strip is roughly half the size of that required for the NIF and LMJ. During initial test runs several tons of laser glass have been produced. Scale-up to full size will occur in 1997.

Schott Technologies Incorporated (Duryea, $\mathrm{Pa}$ ) is also designing a continuous laser glass melting system and has done a demonstration run of continuous forming of a surrogate glass (BK-7) at the required size. This size represents the largest cross-section of glass formed by continuous strip operations. For these tests Schott used a borosilicate glass BK-7 which is a well known optical glass and under continuous production at Schott. Schott will complete construction of a full size melter in 1997 with operational tests to follow. 


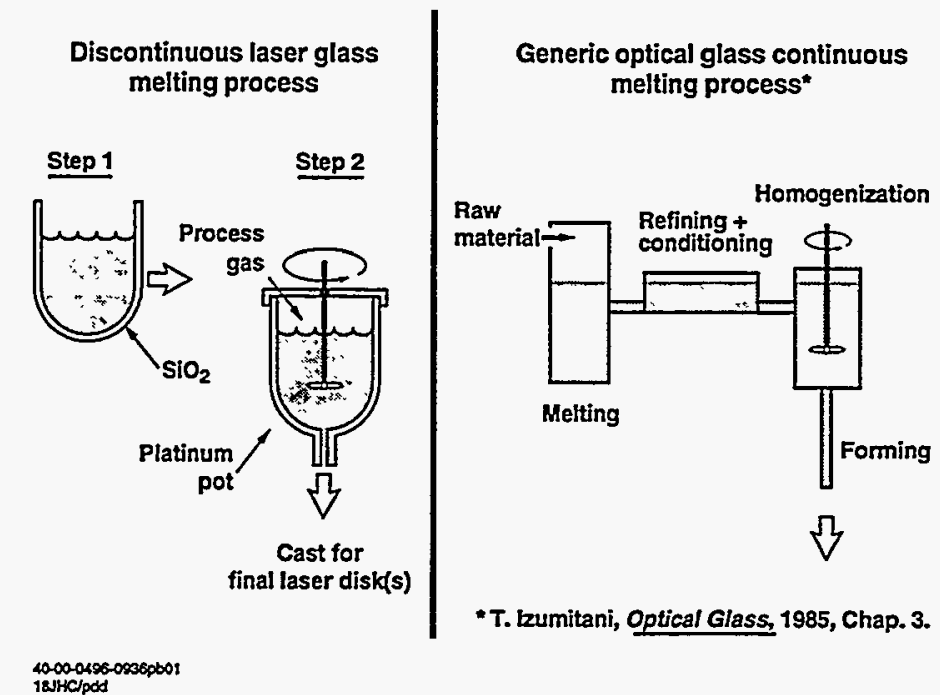

Figure 13. Schematic drawing comparing one-at-a-time laser glass melting process currently in use with the advanced continuous melting process under development at Hoya Corporation and Schott Glass Technologies.

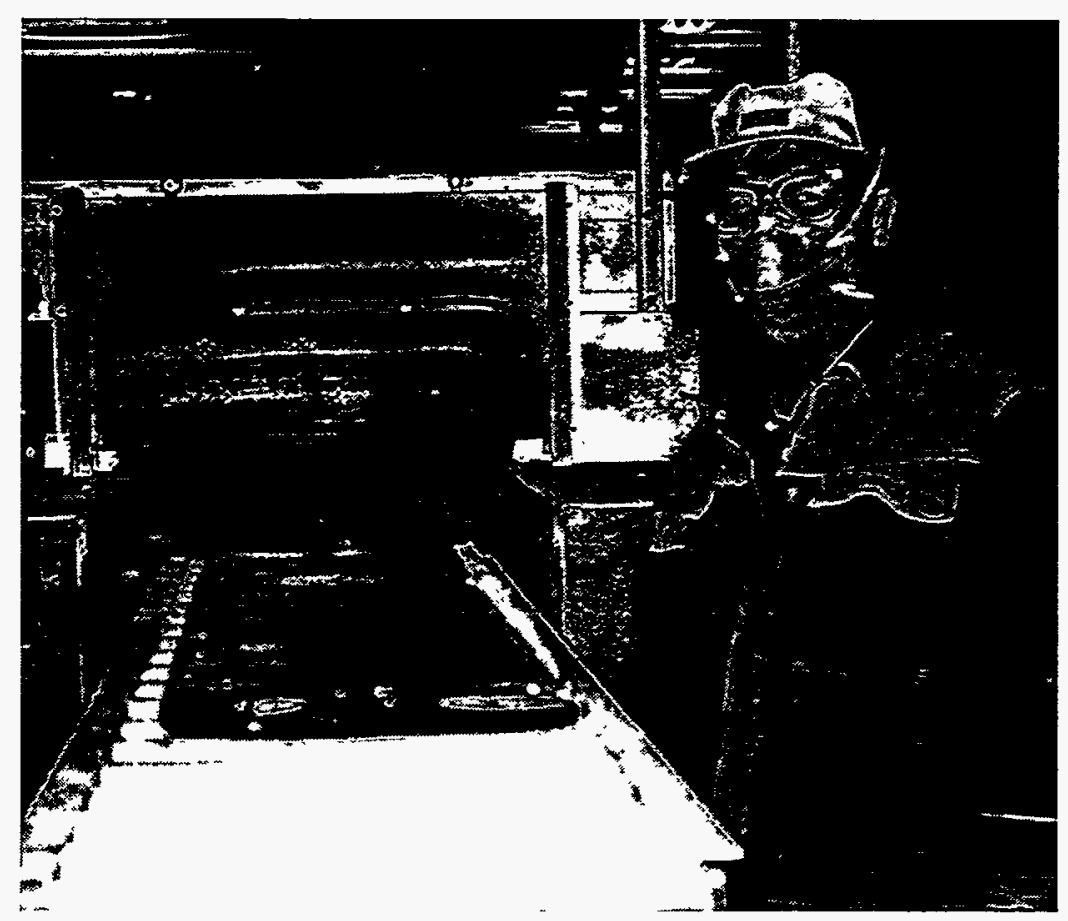

Figure 14. Photograph showing a continuous strip of laser glass $\left(28 \times 240 \mathrm{~mm}^{2}\right)$ exiting the course annealing lehr from a continuous melting and forming laser glass system under development at Hoya Corporation. 


\section{ACKNOWLEDGMENTS}

The author gratefully acknowledges the many helpful discussions with his co-workers particularly Steve Payne and John Caird at LLNL, Joe Hayden and Alex Marker at Schott Glass Technologies, Inc., and Yoshi Toratani and Kunio Takeuchi at Hoya Corporation. The assistance of Gloria Martinez and Bill Steele in the initial literature search for this review is also deeply appreciated. Work performed under the auspices of the U.S. Department of Energy by Lawrence Livermore National Laboratory under Contract No. W-7405-Eng-48.

\section{REFERENCES}

1. S. T. Davey, B. J. Ainslie and R. Wyatt, "Waveguide glasses", Handbook of Laser Science and Technology, M. J. Weber Ed., p. 635-668, CRC Press Inc. 1995.

2. M. J. Weber, "Science and technology of laser glass," J. of Non-Cryst. Solids, Vol. 123 , p. 208-222 (1990).

3. N. Neuroth, "Laser glass: status and prospects," Optical Engineering, vol. 26, 1987, 96.

4. S. E. Stokowski, "Laser glass: an engineered material," LLNL Report UCRL-96331 (1987).

5. R. Reisfeld, M. Eyal, C. K. Jorgensen, "Comparison of laser properties of rare-earths in oxide and fluoride glasses," J. Less-Common Met., 126, p. 187-194 (1986).

6. M. J. Weber, "Laser glasses," Lawrence Livermore National Laboratory, CA, UCRLUC-109922, Conf. \#9206141-2.

7. S. E. Stokowski, R. A. Saroyan and M. J. Weber, " Nd-doped laser glass spectroscopic and physical properties," Lawrence Livermore National Laboratory Report M-095, Rev. 2 Vol. 1 and 2, 1981.

8. N. E. Alekseev, V. P. Gapontsev, M. E. Zhabotinskii, V. B. Kravchenko, and Yu. P. Rudnitskii, "Laser phosphate glasses" (Nauka, Moscow, 1980); English translation in report UCRL-TRANS-11817, Lawrence Livermore National Laboratory, (1983), pp. 3-97.

9. S. E. Stokowski, "Glass lasers," Handbook of Laser Science and Technology, Vol. 1, Lasers and Masers, M J. Weber ed., CRC press, Boca Raton, Fl, 1982, p. 215.

10. J. E. Marion and M. J. Weber, "Phosphate laser glasses," European Journal of Solid State and Inorganic Chemistry, Vol. 28, p. 271-287 (1991).

11. C. F. Rapp "Laser Glasses: Bulk Glasses, " CRC Handbook of Laser Science and Technology, M. J. Weber, Ed., Section 17.1 pp. 619-634, 1995.

12. S. G. Lunter, A. A. Dymnikov, A. K. Przhevuskii, Y. K. Fedorov, "Laser glasses," Conf. on Glasses for Optoelectronics II, SPIE, Vol. 1513, p. 349-359 (1991).

13. (a) Gan Fuxi, "Research and development of laser glasses in China," Chinese Physics Vol. 5, 1985, p. 145-156, Jan.-March 1985 and (b) Z. Jiang, X. Song and J. Zhang, "Studies of laser phosphate glasses," Glass Division Meeting of the Conference of the Chinese Silicates Society, October, 1980, LLNL Translation, UCIR-1683 (1987).

14. J. Marion, "Appropriate use of the strength parameter in solid state slab laser design," J. Applied Phys., Vol. 60, 1986, p. 69. 
15. J. E. Marion, "Strengthened solid-state laser materials," Appl. Phys. Lett., 47(7), 694-696 (1985).

16. J. E. Marion, "Development of high strength solid state laser materials," vol. 146, 1986, p. 234.

17. L. M. Frantz and J. S. Nodvik, "Theory of pulse propagation in a laser amplifier, " $J$. Appl. Phys., Vol. 34, pp. 2346-2349 (1963).

18. H. T. Powell A. C. Erlandson. K. S. Jancaitis and J. E. Murray, "Flashlamp pumping of Nd: glass disk amplifiers," High power Solid State Lasers and Applications, SPIE proceedings Vol. 1277, pp. 103-120, Bellingham, WA, 1990.

19. A. C Erlandson, K. S. Jancaitis, R. W. McCracken and M. D. Rotter, "Gain uniformity and Amplified Spontaneous Emission in Multi-segment Amplifier," ICF quarterly report, Vol. 2, No 3, April-June 1994

20. W. E. Martin and D. Milam, "Gain saturation in Nd: doped laser materials," IEEE J. Quantum Electron. OE-18, 1155 (1982).

21. W. E. Martin and D. Milam, "Gain Saturation in Nd: doped laser materials," IEEE J. Quantum Electron., Vol. QE-18, pp. 1155-1163 (1982).

22. National Ignition Facility Conceptual Design Report, Vol. 2 and 3, Lawrence Livermore National Laboratory, Livermore, CA, Report No. UCRL-PROP-117093, May 1994

23. B. R. Judd, "Optical absorption intensities of rare-earth ions," Phys. Rev., 127, 750 (1962).

24. G. S. Ofelt, "Intensities of crystal spectra of rare-earth ions," J. Chem. Phys., 37, 511 (1962).

25. J. A. Caird, A. J. Ramponi, and P. R. Staver, "Quantum efficiency and excited state relaxation dynamics in neodymium-doped phosphate laser glasses," J. Opt. Soc. Am. B $\underline{8}, 1391$ (1991).

26. S. A. Payne, C. D. Marshall, A. Bayramian, G. D. Wilke, J. S. Hayden, 'Laser properties of a new average-power Nd-doped phosphate glass," Appl. Phys. B (Lasers and Optics) ,Vol. B61, p. 257-266, 1995.

27. S. A. Payne, M. L. Elder, J. H. Campbell, G. D. Wilke, M. J. Weber, and Y. T. Hayden, "Spectroscopic properties of $\mathrm{Nd}^{3+}$ dopant ions in phosphate laser glass," Ceramic Transactions: Solid State Optical Materials, Vol. 28, pp. 253-260, American Ceramic Society Press., 1992.

28. C. B. Layne, W. H. Lowdermilk and M. J. Weber; "Multiphonon relaxation of rareearth ions in oxide glasses," Phys. Rev. B, vol.16 p. 10 (1977).

29 H. Toratani, "Properties of laser glasses," Ph.D. Thesis, Kyoto University, Japan, (1989), pp. 1-187.

30. H. Toratani, I. Izumitani, and H. Kuroda "Compositional dependence of non-radiative decay rate in Nd laser glasses," J. Non-Cryst. Solids, Vol. 52, pp. 303-313, 1982.

31. J. T. Hunt and D. R. Speck, "Present and future performance of the Nova laser system," Optical Engineering, Vol. 28, pp. 461-468, 1989.

32. J. T. Hunt, K. R. Manes and P. A. Renard, "Hot images from obscurations," Applied Optics, Vol. 32, pp. 5973-5982 (1993).

33. N. L. Boling, A. J. Glass and A. Owyoung, "Empirical relationships for predicting non-linear refractive-index changes in optical solids," IEEE J. Quantum Electron. QE-14, 601 (1978). 
34. K. A. Cerqua, S. D. Jacobs, and A. Lindquist, "Ion-exchange strengthened phosphate laser glass. Development and applications," J. Non-Cryst. Solids, Vol.93, p.361-376 1987.

35. W. D. Kingery, H. K. Bowen and D. R. Uhlmann, Introduction to Ceramics, John Wiley and Sons, New York, 2nd ed., 1976, Chapter 16.

36. M. L. Elder, Y. T. Hayden, J. H. Campbell, S. A. Payne, and G. D. Wilke, "Thermal-mechanical and physical-chemical properties of phosphate laser glasses," Ceramic Transactions: Solid State Optical Materials, Vol. 28, pp. 261-282, American Ceramic Society Press., 1992.

37. J. S. Hayden, Y. T. Hayden and J. H. Campbell, "Effect of composition on the thermal, mechanical, and optical properties of phosphate laser glasses," High-Power Solid State Lasers and Applications, SPIE vol. 1277, pp. 121-139 (1990).

38. Y. T. Hayden, J. H. Campbell, S. A. Payne and G. D. Wilke, "Effect of phosphate glass composition on the rate of platinum dissolution," Ceramic Transactions: Solid State Optical Materials, Vol. 28, pp. 283-296, Amer. Ceram. Society Press, 1992.

39. T. Izumitani, M. Matsukawa and H. Miyade, "Solubility of Pt in Nd Phosphate laser glass," Laser Induced Damage in Optical Materials: 1987, NIST special publication 756, pp. 29-34 (1988).

40. J. H. Campbell, E. P. Wallerstein, J. S. Hayden, D. L. Sapak, D. Warrington, A. J. Marker, H. Toratani, H. Meissner, S. Nakajima, and T. Izumitani, "Elimination of platinum inclusions in phosphate laser glasses," Lawrence Livermore National Laboratory Report UCRL-53932, Livermore, CA, 1989, pp. 1-80.

41. J. H. Campbell, E. P. Wallerstein, J. S. Hayden, D. L. Sapak, and A. J. Marker, "Effects of melting conditions on platinum-inclusion content in phosphate laser glasses," Glastech. Ber. Glass Sci. Technol., Vol. 68, No. 1, pp. 11-21, 1995.

42. J. H. Campbell, E. P. Wallerstein, H. Toratani, H. Meissner, and T. Izumitani , "Effects of process gas environment on platinum-inclusion density and dissolution rate in phosphate laser glasses," Glastech. Ber. Glass Sci. Technol., Vol. 68, No. 2, pp. 1-11, 1995.

43. T. Izumitani, H. Toratani and H Kuroda, J. Non-Cryst. Solids, Vol. 42, 1982, p.87.

44. J. S. Hayden, M. K. Aston, S. A. Payne, M. L. Elder, J. H. Campbell, "Laser and thermo-physical properties of neodymium-doped phosphate glasses," Proc. SPIE-Int. Soc. Opt. Eng. vol. ,1993, p. 1761.

45. Y. Nageno, $\mathrm{H}$. Takebe and $\mathrm{K}$. Morinaga, "Correlation between radiative transition probabilities of $\mathrm{Nd}^{3+}$ and composition in silicate, borate and phosphate glasses," $J$. Am. Ceram. Soc., Vol. 76, pp. 381-86 (1993).

46. H. Takebe, K. Morinaga and T. Izumitani "Correlation between radiative transition probabilities of rare-earth ions and composition in oxide glasses," J. Non-Cryst. Solids, Vol. 178, pp. 58-63, (1994).

47. H. Takebe, Y. Nageno, and K. Morinaga "Effect of Network modifier on spontaneous emission probabilities of $\mathrm{Er}^{3+}$ in oxide glasses," J. Am. Ceram. Soc., Vol. 77, pp. 2132-2136 (1994).

48. S. Tanabe, T. Hanada, T. Ohyagi and N. Soga "Correlation between ${ }^{151} \mathrm{Eu}$ Mössbauer isomer shift and Judd-Ofelt $\Omega_{6}$ parameters of $\mathrm{Nd}^{3+}$ ions in phosphate and silicate laser glasses" Phys. Rev. B, Vol. 48, pp. 10591-10594 (1993).

49. S. Tanabe, T. Ohyagi, S. Todoroki, T. Hanada, and N. Soga, J. Appl. Phys, vol. 73, 1993, p.8451. 
50. D. T. Bowron, G. A. Saunders, R. J. Newport, B. D. Rainford, H. B. Senin, "EXAFS studies of rare-earth metaphosphate glasses," Phys. Rev. B (Condensed Matter) Vol. 53, 1996, p. 5268-5275.

51. J. H. Campbell, R. T. Maney, L. J. Atherton, R. C. Montesanti, J. J. DeYoreo, L. M. Sheehan, M. R. Kozlowski, and C. E. Barker, "Large-aperture high-damage threshold optics for Beamlet," Inertial Confinement Fusion Quarterly Report, Vol. 5, No. 1, pp. 29-41, Lawrence Livermore National Laboratory, Livermore, CA, UCRLLR-105821-95-1, October-December 1994.

52. D. L. Sapak, J. M. Ward and J. E. Marion, "Impurity absorption coefficient measurements in phosphate glass melted under oxidizing conditions" in Properties and Characteristics of Optical Glass, SPIE, Vol. 970, pp. 107-112, (1988).

53. S. E. Stokowski and D. Krashkevich, "Transition-metal ions in Nd-doped glasses: spectra and effects on Nd fluorescence," Mat. Res. Soc. Symp. Proc., Vol. 61, 1986 (pp. 273).

54. J. A. Caird, F. P. Milanovich, N. D. Nielsen, H. T. Powell, J. E. Marion, A. J. Pertica, and J. N. Roe, "Passive optical losses in laser glass," presented at CLEO Conf., Baltimore, MD, Lawrence Livermore National Laboratory, UCRL-100012, April 24-28, 1989.

55. S. Stokowski, private commun., LLNL internal doc., LRD 87-073, April 1987.

56. A. J. Ramponi and J. A. Caird, "Fluorescence quantum efficiency and optical heating efficiency in laser crystals and glasses by laser calorimetry," $J$ of Appl. Phys., Vol. 63, p. 5476-5484 (1988).

57. J. Caird, private commun., LLNL internal doc., ADG 88-138, Dec. 1988.

58. Y. Jiang, S. Jiang, Y. Jiang, "Spectral properties of neodymium( $3+$ in aluminophosphate glasses," J. Non-Cryst. Solids ,Vol.112, 1988, p.286-90.

59. D. Zhuo, W. Zu, Y. Jiang, "Water in phosphate laser glasses and its removal," Chinese Physics Vol. 6, p.157-161, 1986.

60. H. Ebendorff-Heidepriem and D. Ehrt, "Determination of the $\mathrm{OH}$ content of glasses", Glass Sci. Technol. vol. 68, 1995, pp.139-146.

61. T. H. Förster, Ann. Phys. Vol. 2, p.55, 1948.

62. A. I. Burshtein, Sov. Phys, JETP, Vol. 35, pp. 882, 1972.

63. J-O. Byun, B-H. Kim, K-S. Hong, H-J. Jung, S-W. Lee, K-S. Ryoo, A. A. Izyneev, V. B. Kravchenko, "Spectral properties of $\mathrm{Nd}^{3+}$-doped $\mathrm{RO}-\mathrm{Na}_{2} \mathrm{O}-\mathrm{Al}_{2} \mathrm{O}_{3}-\mathrm{P}_{2} \mathrm{O}_{5}(\mathrm{R}$ $\mathrm{Mg}, \mathrm{Ca}, \mathrm{Ba}$ ) glass system," Jpn. J. Appl. Phys., Part 1, vol. 33(9A), p. 4907-4912 1994.

64. J. H. Campbell, F. Rainer, M. Kozlowski, C. R. Wolfe, I. M. Thomas, F. Milanovich, "Damage resistant optics for a mega-joule solid-state laser," Laser Induced Damage in Optical Materials: 1990, SPIE, Vol. 1441, p. 444-456,1990.

65. C. L. Weinzapfel, G. J. Greiner, C.D. Walmer, J. K. Kimmons, E. P. Wallerstein, F. T. Marchi, J. H. Campbell, J. S. Hayden, K. Komiya, and T. Kitiyama, "Large scale damage testing in a production environment," Laser Induced Damage in Optical Materials: 1987, NIST Special Publication 756, National Institute of Standards and Technology, 1987, pp. 112-122

66. R. Gonzales and D. Milam "Evolution during multiple-shot irradiation of damage surrounding isolated platinum inclusions in phosphate laser glasses," Laser Induced Damage in Optical Materials; 1985, NBS special pub. No. 745, (1988) pp. 128-137. 
67. J. H. Campbell, "Modeling platinum-inclusion dissolution in phosphate laser glasses," Glass Sci. Technol., Vol. 68, pp. 91-101, 1995.

68. "PCS-7 Glass", Hoya product brochure, Hoya Corp., Fremont, Ca, (1995).

69. J. H. Kelly, M. H. Shoup, III, M. M. Tedrow, "The effect of ionic and particulate platinum on the performance of large-aperture Nd: phosphate glass rod amplifiers," SPIE, Vol. 1627, p. 175-181 (1992).

70. T. Izumitani, and $\mathrm{H}$. Toratani, "Temperature Coefficient of Electronic Polarizability in Optical Glasses," J. Non-Cryst. Solids, Vol. 49, 1980, pp. 611-619.

71. J. H. Campbell et. al "Development of Composite Polymer-glass Edge Claddings for Nova Laser Disks, "Laser Induced Damage in Optics Materials: 1986, NIST special publication 752, pp. 19-41 (1988).

72. B. M. Van Wonterghem, J. R. Murray, J. H. Campbell, D. R. Speck, C. E. Barker, I. C. Smith, D. F. Browning and W. C. Behrendt, "System description and initial performance results for Beamlet," Inertial Confinement Fusion Quarterly Report, Vol. 5, No. 1, pp. 1-17, Lawrence Livermore National Laboratory, Livermore, CA, UCRL-LR-105821-95-1, October-December 1994.

73. W. A. Bookless, Ed., "The National Ignition Facility," Energy and Technology Review, Vol. 12, Lawrence Livermore National Laboratory, Livermore, CA, Report UCRL-52000-94-12, December 94,.

74. M. Andre, M. Novaro, D. Schirmann, "Technologie pour un laser Megajoules," Chocs, Revue scientifique et technique de la Direction de Applications Militaires, Vol. 13, pp. 73-84, April 95.

75. J. S. Hayden, D. L. Sapak, and H. J. Hoffman, "Advances in glasses for high average power laser systems," Conf. on High Power Solid State Lasers, SPIE, Vol.1021, p.36-41 (1989).

76. T. Izumitani, M. Matsukawa, C. Hata, K. Tanaka, and H. Toratani "Development of silicophosphate glass, HAP-3," Laser Induced Damage in Optical Materials: 1986, NIST Publication 752, 1988, p.13

77. C. Hata, T. Inazumi, T. Izumitani, "Chemically-strengthened slab laser glass with optical surface quality," Laser Induced Damage Opt. Mater.: 1986, NIST Spec. Publ., 752, p. 168-175, 1988.

78. H. C. Lee and H. E. Meissner, "Ton-exchange strengthening of high average power phosphate laser glass," SPIE. vol. 1441, 1991, p. 87-103.

79. (a) S. Jiang, J. D. Myers, R. Wu, G. M. Bishop, D. L. Rhonehouse, M. J. Myers, S. J. Hamlin, "Chemically strengthened $\mathrm{Er}^{3+}, \mathrm{Nd}^{3+}$ doped phosphate laser glasses," SPIE vol. 2379, p. 17-25, 1995 and (b) U. Griebner, R. Koch, H. Schunnagel, S. Jiang, M. J. Myers, D. Rhonehouse and S. Hamlin, "Laser performance of a new ytterbium doped phosphate laser glass", OSA Proc. of Advanced Solid State Lasers, 1996, pp.1-4.

80. K. A. Cerqua, A. Lindquist, S. D. Jacobs, J. Lambropoulos, "Strengthened glass for high average power laser applications," Conf. on New Slab and Solid-State Laser Technologies and Applications, SPIE, Vol. 736, p. 13-21 (1987).

81. V. A. Buchenkov, A. I. Stepanov, M. N. Tolstoi, V. V. Shashkin, "Measurements of the thermal strength of neodymium-glass laser active elements," Soviet Journal of Optical Technology, Vol. 54, p. 6-8, 1987.

82. I. F. Balashov, B. G. Berezin, V. N. Ivanov, Yu. T. Nagibin, Yu. K. Fedorov, A. V. Sharkov, and O. S. Shchavelev, "Thermal strength of phosphate-glass active elements," Soviet Journal of Optical Technology, Vol. 58, p. 564-567 (1991). 
83. A. J. Marker, "Optical glass technology," Geometrical Optics, SPIE Proceedings Vol. 531, pp. 2-10, 1985.

84. T. S. Izumitani, Optical Glass, Chap. 3, Am. Instit. of Phys. translation series, New York, 1986.

85. T. Izumitani, "Continuous melting of phosphate laser glass," SPIE, Vol. 2633, p. 386, 1995.

86. R. Page and G. Wilke, Private communication, Lawrence Livermore National Laboratory, 1996. 


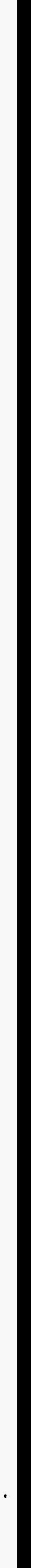

